\title{
Advanced Tracers in PET Imaging of Cardiovascular Disease
}

\author{
Yesen Li, ${ }^{1,2}$ Wei Zhang, ${ }^{3,4}$ Hua Wu, ${ }^{1}$ and Gang Liu' ${ }^{2}$ \\ ${ }^{1}$ Department of Nuclear Medicine, The First Affiliated Hospital of Xiamen University, Xiamen 361003, China \\ ${ }^{2}$ Center for Molecular Imaging and Translational Medicine, School of Public Health, Xiamen University, Xiamen 361102, China \\ ${ }^{3}$ Department of Orthopedics, Sichuan Academy of Medical Sciences \& Sichuan Provincial People's Hospital, Chengdu 610072, China \\ ${ }^{4}$ Sichuan Key Laboratory of Medical Imaging, North Sichuan Medical College, Nanchong 637007, China
}

Correspondence should be addressed to Gang Liu; gangliu.cmitm@xmu.edu.cn

Received 21 February 2014; Revised 7 July 2014; Accepted 8 August 2014; Published 15 October 2014

Academic Editor: Ali Gholamrezanezhad

Copyright (C) 2014 Yesen Li et al. This is an open access article distributed under the Creative Commons Attribution License, which permits unrestricted use, distribution, and reproduction in any medium, provided the original work is properly cited.

Cardiovascular disease is the leading cause of death worldwide. Molecular imaging with targeted tracers by positron emission tomography (PET) allows for the noninvasive detection and characterization of biological changes at the molecular level, leading to earlier disease detection, objective monitoring of therapies, and better prognostication of cardiovascular diseases progression. Here we review, the current role of PET in cardiovascular disease, with emphasize on tracers developed for PET imaging of cardiovascular diseases.

\section{Introduction}

Cardiovascular diseases are progressive and there are a number of physiological and morphological changes that occur with aging that could alter cardiovascular function and subsequently increase risk of cardiovascular disease [1]. Despite considerable advances in prevention and treatment over the last decades, cardiovascular diseases remain the most frequent causes of death worldwide and represent a great challenge for modern research and medicine. To address this requires urgent development of sensitive and noninvasive methods for early detection and personalized treatment of cardiovascular diseases [2].

Traditional medical imaging techniques have been routinely used to provide early diagnoses and prognosis of cardiovascular diseases [3]. Ideally it would be possible to detect molecular and cellular processes early and characterize cardiovascular diseases before manifestation of gross anatomical features or physiological consequences. Current advanced molecular imaging modalities include positron emission tomography (PET), single photon emission computed tomography (SPECT), magnetic resonance imaging (MRI), and optical imaging, all of which could provide critical molecular and cellular level information for early diagnostics, advanced therapeutics, and better understanding of fundamental biological processes of cardiovascular disease [4-6].

Nuclear cardiac imaging has been indisputably the most reliable and accurate technique for noninvasive function characterization of coronary artery disease (CAD) [7]. Due to its clinical success in oncology, the availability of PET systems has increased dramatically since it was developed in 1975 [8], and as such has been able to contribute to the growth in cardiac imaging [9]. Generally, PET imaging with appropriate tracers is considered to have superior diagnostic accuracy for the detection of cardiovascular diseases [10, 11]. For example, myocardial perfusion imaging (MPI) with PET has superior diagnostic accuracy and safety profile, and it provides powerful and incremental risk stratification for patients with suspected or known CAD [12]. Furthermore, PET imaging with $\left[{ }^{18} \mathrm{~F}\right]$-fluorodeoxyglucose $\left(\left[{ }^{18} \mathrm{~F}\right] \mathrm{FDG}\right)$ has been the gold standard for myocardial metabolism assessment [13].

Recent advances in radiopharmaceuticals, hardware, and software of cardiac PET imaging have improved the diagnostic accuracy and risk assessment of patients with suspected cardiac disorders [14-17]. For example, the rapid evolution of hybrid PET/CT and PET/MR imaging with the advanced tracers has provided a new perspective on cardiac imaging by providing combined anatomic and functional evaluation of coronary disease and alterations in cardiac function. Because 
TABLE 1: Commonly used positron emitting radionuclides.

\begin{tabular}{|c|c|c|c|c|}
\hline Nuclide & Physical half-life (min) & Maximum energy $(\mathrm{MeV})$ & Tissue positron range $(\mathrm{mm})^{\mathrm{a}}$ & Radionuclide production \\
\hline${ }^{18} \mathrm{~F}$ & 110 & 0.64 & 0.54 & Cyclotron \\
\hline${ }^{11} \mathrm{C}$ & 20.3 & 0.97 & 0.96 & Cyclotron \\
\hline${ }^{13} \mathrm{~N}$ & 10 & 1.20 & 1.26 & Cyclotron \\
\hline${ }^{15} \mathrm{O}$ & 2 & 1.74 & 1.87 & Cyclotron \\
\hline${ }^{82} \mathrm{Rb}$ & 1.27 & 3.38 & 4.10 & Generator \\
\hline${ }^{99 m} \mathrm{Tc}$ & 293.3 & 3.23 & $\mathrm{~N} / \mathrm{A}$ & Cyclotron \\
\hline${ }^{68} \mathrm{Ga}$ & 67.7 & 1.90 & 2.12 & Generator \\
\hline${ }^{64} \mathrm{Cu}$ & 761.4 & 0.653 & N/A & Cyclotron \\
\hline
\end{tabular}

${ }^{a}$ Calculated for soft tissue using the full width at $20 \%$ of the maximum amplitude (FW20M) method [28].

of the pivotal role of tracers in the realization of the power of cardiac PET imaging, the design and development of tracers is becoming one of the major subjects of cardiac PET imaging [18]. In this paper, we review the present state and future of cardiac PET imaging, with a focus on PET tracers and their utility in cardiovascular diseases.

\section{PET: State-of-the-Art Modality for Cardiac Diagnostics}

PET is advantageous among nuclear medicine imaging modalities, because some positron emitting isotopes (e.g., C, N, and $\mathrm{O}$ ) are the principal constituents of bioorganic molecules and can be labeled to the bioorganic molecules without change to their physicochemical and biochemical properties. The most widely used radionuclide ${ }^{18} \mathrm{~F}$ is generally not a constituent of biomolecules but a bioisostere of a hydrogen or hydroxyl group [10]. Table 1 shows the PET radionuclides commonly used in cardiovascular disease imaging, which are often produced by cyclotron, except for ${ }^{82} \mathrm{Rb}$ and ${ }^{68} \mathrm{Ga}$.

SPECT myocardial perfusion imaging is considered a reliable and widely available tool for use by physicians in cases of cardiovascular disease. However, recent studies have shown that PET offers increased accuracy and improved sensitivity compared to SPECT [19]. Indeed, several PET myocardial perfusion tracers (e.g., $\left[{ }^{82} \mathrm{Rb}\right] \mathrm{RbCl},\left[{ }^{13} \mathrm{~N}\right] \mathrm{NH}_{3}$, and $\left[{ }^{15} \mathrm{O}\right] \mathrm{H}_{2} \mathrm{O}$ ) used for assessment of myocardial perfusion have produced higher quality images than technetium SPECT imaging [20].

In addition, PET has several technical advantages over SPECT: (1) most importantly PET has 2-3 orders of magnitude higher sensitivity than SPECT and the spatial resolution of PET can reach $4 \mathrm{~mm}$ compared to $10-12 \mathrm{~mm}$ in wholebody SPECT scans, or $6-7 \mathrm{~mm}$ in new dedicated cardiac SPECT equipment (i.e., CZT cameras) [21, 22]; (2) PET has much higher temporal resolution than SPECT [19], with a hybrid PET/CT system providing accurate depthindependent attenuation correction [23]; (3) PET tracers have a shorter physical half-life and higher extraction fractions compared to SPECT tracers, leading to less radiation burden to patients and superior image quality in comparison to standard SPECT $[24,25]$, particularly for cases where image quality can be degraded with SPECT, such as in obese patients or in women where a breast attenuation artifact could lead to a false positive result [24]. Furthermore, the use of 3D acquisitions represents an important milestone in myocardial perfusion PET imaging and could significantly shorten imaging protocols, reduce radiation exposure, and increase its use in PET cardiac imaging $[26,27]$.

\section{MPI Tracers}

MPI is a noninvasive test that involves injection of a small amount of radioactive tracer into the body to depict the distribution of blood flow to the heart. MPI is used to identify areas of reduced blood flow (perfusion) to the heart muscle which may indicate CAD. Due to its high sensitivity and temporal resolution MPI with PET is considered the gold standard for quantifying myocardial perfusion $(\mathrm{mL} / \mathrm{min} / \mathrm{g})$, both at rest and during stress [24].

To achieve high quality imaging, an ideal PET myocardial perfusion tracer (1) should have a high first-pass extraction fraction from blood to tissue and retention in the heart, while allowing a low clearance from tissue to blood at baseline to high flow rates; (2) the myocardial tracer uptake should correlate with the blood flow rate; (3) should have minimal uptake and retention in the lungs and liver to avoid interference with myocardial imaging; with long retention in cardiac tissue and in vivo stability; (4) could be synthesized efficiently, reliably, and with full automation; (5) should have a relatively long half-life and be possible to distribute to institutes without an on-site cyclotron [2]. However, many of the PET myocardial perfusion tracers are unfavorable for MPI.

The currently used PET myocardial perfusion tracers are $\left[{ }^{15} \mathrm{O}\right] \mathrm{H}_{2} \mathrm{O},\left[{ }^{13} \mathrm{~N}\right] \mathrm{NH}_{3}$, and $\left[{ }^{82} \mathrm{Rb}\right] \mathrm{RbCl}$. $\left[{ }^{15} \mathrm{O}\right] \mathrm{H}_{2} \mathrm{O}$ is metabolically inert and can diffuse freely across the capillary and cellular membranes, leading to the ideal first-pass extraction fraction as shown in Figure 1. Thus, the net extraction correlates linearly with blood flow [29, 30], which is considered ideal for measuring myocardial blood flow [31]. In addition, the short physical half-life of $\left[{ }^{15} \mathrm{O}\right] \mathrm{H}_{2} \mathrm{O}$ could afford multiple flow measurements at short intervals. However, a comparison study of $\left[{ }^{15} \mathrm{O}\right] \mathrm{H}_{2} \mathrm{O}$ versus $\left[{ }^{13} \mathrm{~N}\right] \mathrm{NH}_{3}$ for quantification of myocardial blood flow in humans found that $\left[{ }^{15} \mathrm{O}\right] \mathrm{H}_{2} \mathrm{O}$ yielded more heterogeneous estimates of regional myocardial blood flow than $\left[{ }^{13} \mathrm{~N}\right] \mathrm{NH}_{3}$ [32] and that because of its freely diffusible nature $\left[{ }^{15} \mathrm{O}\right] \mathrm{H}_{2} \mathrm{O}$ is not retained in the myocardium. Therefore, $\left[{ }^{15} \mathrm{O}\right] \mathrm{H}_{2} \mathrm{O}$ uptake between the 


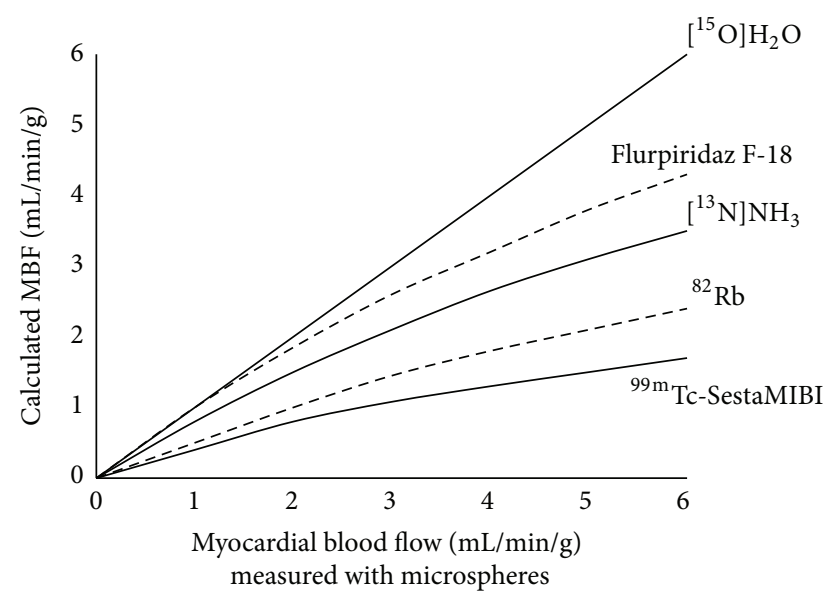

FIGURE 1: Correlation between the calculated myocardial blood flow $(\mathrm{MBF})$ base imaging studies with myocardial perfusion tracers and the expected MBF $[2,122]$.

myocardium and blood pool reach equilibrium rapidly, making it impossible to distinguish ventricular from myocardial activity and thereby precludes generating appropriate images of myocardial perfusion. $\left[{ }^{15} \mathrm{O}\right] \mathrm{CO}$, which permits labeling of the vascular volume, has been used in combination with $\left[{ }^{15} \mathrm{O}\right] \mathrm{H}_{2} \mathrm{O}$ for correction of the high ${ }^{15} \mathrm{O}$ activity in the blood pool [33]. However, mathematical models could be used to produce parametric imaging of perfusion without additional $\left[{ }^{15} \mathrm{O}\right] \mathrm{CO}$ blood pool scan sequences $[34,35]$. Additionally, due to its short half-life $\left[{ }^{15} \mathrm{O}\right] \mathrm{H}_{2} \mathrm{O}$ requires an on-site cyclotron. Although these limits have hampered the use of $\left[{ }^{15} \mathrm{O}\right] \mathrm{H}_{2} \mathrm{O}$ for PET perfusion imaging in routine clinical practice, due to its excellent radiokinetic properties, $\left[{ }^{15} \mathrm{O}\right] \mathrm{H}_{2} \mathrm{O}$ has gained wide popularity for research purposes $[36,37]$.

${ }^{82} \mathrm{Rb}$ is a generator product with a physical half-life of $76 \mathrm{~s}$, which acts as a potassium analogue and is taken up by the energy-dependent $\mathrm{Na} / \mathrm{K}$-ATPase and extracted similarly to thallium-201 and lower to ${ }^{13} \mathrm{~N}$-ammonia and ${ }^{15} \mathrm{O}$ water [24]. Studies have demonstrated that PET MPI with ${ }^{82} \mathrm{Rb}$ performs superior to SPECT in sensitivity, image quality, interpretive certainty, and diagnostic accuracy [38, 39]. With a single rest and pharmacologic stress ${ }^{82} \mathrm{Rb}$ PET/CT scanning, Kim et al. have demonstrated that the combination of MPI, coronary artery calcium (CAC), coronary flow reserve (CFR), and thoracic aorta calcium (TAC) has complementary roles in intermediate risk patients [40]. Due to its distinct advantage of not requiring an on-site cyclotron, ${ }^{82} \mathrm{Rb}$ is the most frequently used clinical myocardial perfusion PET tracer, and the clinical application of ${ }^{82} \mathrm{Rb}$ and PET for myocardial perfusion imaging is expected to grow. The acquisition time of PET/CT protocols with ${ }^{82} \mathrm{Rb}$ requires only $25-30 \mathrm{~min}$, compared to at least $2.5 \mathrm{~h}$ and as much as $4 \mathrm{~h}$, for SPECT strategies [41]. Moreover, the radiation exposure from cardiac imaging procedures is reasonably low due to its ultrashort physical half-life [42].

However, there are some limitations associated with the use of ${ }^{82} \mathrm{Rb}$. Firstly, ${ }^{82} \mathrm{Rb}$ has the lowest myocardial extraction fraction (65\% of first-pass extraction) among the currently available PET perfusion tracers, and its nonlinear extraction at higher flow leads to underestimation of $\operatorname{MBF}[43,44]$. Secondly, the maximum kinetic energy of ${ }^{82} \mathrm{Rb}$ is higher than the other radionuclides shown in Table 1; therefore, the tissue positron range of ${ }^{82} \mathrm{Rb}$ is longer, resulting in a relatively low spatial resolution [36]. Additionally ultrashort half-life of ${ }^{82} \mathrm{Rb}$ can result in oversaturation at the beginning of the acquisition, as well as low count statistics and imaging noise in later phases $[2,44]$. For these reasons, when using ${ }^{82} \mathrm{Rb}$ patients are usually stressed pharmacologically, rather than by exercise [43], while the mode of ${ }^{82} \mathrm{Rb}$ myocardial uptake may also change when cellular metabolism is altered [45]. These factors make ${ }^{82} \mathrm{Rb}$ less than ideal for absolute quantification of myocardial blood flow.

The FDA approved $\left[{ }^{13} \mathrm{~N}\right] \mathrm{NH}_{3}$ for myocardial perfusion imaging in 2000. Although $\mathrm{NH}_{3}$ is a freely permeable to cell membranes and $\mathrm{NH}^{4+}$ is a relatively impermeable cation to cell membranes, the mechanism of cellular localization of $\left[{ }^{13} \mathrm{~N}\right] \mathrm{NH}_{3}$ is not yet fully understood. Diffusing into the cellular membrane followed by trapping by glutamine, glutamic acid, and carbamyl phosphate, is one of the described mechanisms of $\left[{ }^{13} \mathrm{~N}\right] \mathrm{NH}_{3}$ cellular localization [46]. Due to its high first-pass extraction fraction $(>80 \%)$ and linear myocardial uptake over a wide range of $\mathrm{MBF},\left[{ }^{13} \mathrm{~N}\right] \mathrm{NH}_{3}$ is a more practical standard perfusion tracer compared to other tracers [43, 47, 48]. The longer physical half-life (9.8 min) of $\left[{ }^{13} \mathrm{~N}\right] \mathrm{NH}_{3}$ compared to $\left[{ }^{15} \mathrm{O}\right] \mathrm{H}_{2} \mathrm{O}$ leads to prolonged retention in myocardium, preferential distribution into the myocardium, and ultimately better image quality. As $\left[{ }^{13} \mathrm{~N}\right] \mathrm{NH}_{3}$ and $\left[{ }^{15} \mathrm{O}\right] \mathrm{H}_{2} \mathrm{O}$ perform similarly in the estimation of myocardial blood flow in humans [32], an increasing number of publications have demonstrated its substantial diagnostic and prognostic value [49-52]. However, $\left[{ }^{13} \mathrm{~N}\right] \mathrm{NH}_{3}$ myocardial uptake depends not only on perfusion but also myocardial cell viability, metabolic conditions, and the integrity of the cellular membrane, limiting its value as a myocardial perfusion tracer [53].

Flurpiridaz F-18 ( ${ }^{18}$ F-BMS-747158-02) is a derivative of the pyridazinone insecticide pyridaben, which is known to bind tightly to mitochondrial complex I, with high affinity in myocardial tissue $[54,55]$. The high first-pass extraction fraction (94\%) of flurpiridaz F-18 [56] has several advantages, including detection of milder perfusion defects, and better accuracy in reflecting the true extent of perfusion defects compared to ${ }^{201} \mathrm{Tl}$, the ${ }^{99 \mathrm{~m}} \mathrm{Tc}$-labelled tracers, or ${ }^{82} \mathrm{Rb}$. Flurpiridaz F-18 also offers better image quality and higher diagnostic certainty, compared to Tc-99m SPECT [57]. Additionally, compared with $\left[{ }^{13} \mathrm{~N}\right] \mathrm{NH}_{3}$, flurpiridaz F-18 was shown to produce improved contrast and higher resolution, resulting in better delineation of induced perfusion defects with lower injected dose of tracers (Figure 2) [58]. In a phase 1 study using flurpiridaz F-18 no drug-related adverse events were identified, and it was well tolerated in all subjects [59]. A phase II study using flurpiridaz F-18 has proved that PET MPI with flurpiridaz F-18 has a higher sensitivity than SPECT, with an increase in diagnostic certainty for PET versus SPECT [60]. As such, flurpiridaz F-18 might be close to an ideal 


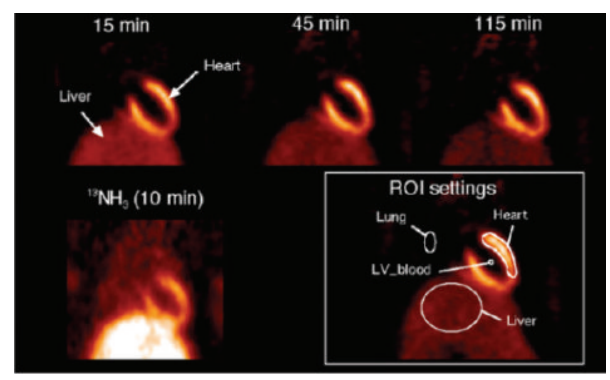

(a)

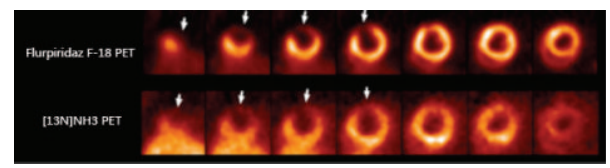

(b)

FIgURE 2: (a) Flurpiridaz F-18 PET images of healthy rat and $\left[{ }^{13} \mathrm{~N}\right] \mathrm{NH}_{3}$ PET image in coronal view. (b) Images of rat with permanent left coronary artery occlusion using Flurpiridaz F-18 PET and $\left[{ }^{13} \mathrm{~N}\right] \mathrm{NH}_{3}$ PET. Arrows indicate localization of myocardial infarction (from [58] with permission).

myocardial perfusion tracer and is currently being evaluated in phase III clinical studies. Exercise stress testing offers important clinical and hemodynamic information in addition to myocardial perfusion. Flurpiridaz F-18 can potentially be used in exercise stress testing by injection of tracer during peak exercise and postinjection imaging because of the longer half-life of ${ }^{18} \mathrm{~F}$. However, the long physical half-life of flurpiridaz F-18 may limit its use in protocols involving repeated measurements on a single day; therefore, protocols involving stress and rest studies should perform on separate days or protocols involving repeated measurements on a single day should correct for the residual activity of the first acquisition and the validity of a tracer reinjection protocol.

Several other ${ }^{18}$ F-labeled perfusion PET tracers have been introduced for the evaluation of myocardial perfusion. Yu et al. [61] found that another mitochondrial complex I inhibitor, ${ }^{18} \mathrm{~F}-\mathrm{RP} 1004$, has a higher initial liver uptake compared to flurpiridaz F-18 ( $\left.{ }^{18} \mathrm{~F}-\mathrm{BMS}-747158-02\right)$, possibly due to the higher lipophilicity of ${ }^{18} \mathrm{~F}-\mathrm{RP} 1004$. Mou et al. [62] synthesized $\left[{ }^{18} \mathrm{~F}\right] \mathrm{FP} 2 \mathrm{OP}$, and biodistribution studies in mice have shown that $\left[{ }^{18} \mathrm{~F}\right] \mathrm{FP} 2 \mathrm{OP}$ has a significant high heart uptake, as well as good heart/liver, heart/lung, and heart/blood ratios and has therefore been proposed as a potential new MPI agent for PET. ${ }^{18}$ F-FTPP is an analog of tetraphenylphosphonium $\left(\mathrm{TPP}^{+}\right)$cation that concentrates in mitochondria, also demonstrated promising characteristics as a PET MPI tracer. Biodistribution and imaging studies with ${ }^{18}$ F-FTPP in rats have shown rapid accumulation of activity in the heart (1-2 min) with stable retention for at least $1 \mathrm{~h}$. Heart uptake of ${ }^{18}$ F-FTPP in occluded heart ROIs was comparable to that of $\left[{ }^{13} \mathrm{~N}\right] \mathrm{NH}_{3}$ in rabbits $[63,64]$. In addition, some coordination compounds of metal radionuclides have been developed for myocardial imaging, such as ${ }^{62} \mathrm{Cu}$-PTSM [65] and ${ }^{68}$ Ga-BAPEN $[63,64]$.

\section{Myocardial Metabolism Imaging}

PET MPI is important for providing insight into substrate "feed" to the heart, while PET imaging of heart metabolism will lead to a deep understanding of the biochemical pathways of the heart and their disease behaviors. Despite rapid growth in our understanding of the relationship between altered myocardial metabolism and cardiac disease, there remains much to learn. There is a growing demand for accurate noninvasive imaging approaches of myocardial substrate metabolism, with one of the most notable application being the assessment of myocardial viability. Myocardial viability studies are crucial for differentiation of patients who can benefit from revascularization and those without myocardial viability, for whom there is no apparent benefit from revascularization over medical therapy.

Myocardial viability refers to dysfunctional myocardium due to ischaemia, but with the potential to recover its function. In patients with ischaemic left ventricular (LV) dysfunction, those with viable myocardium should be considered for revascularization rather than cardiac transplantation, while patients with nonviable myocardium will not benefit from high-risk percutaneous coronary interventions or surgery [66]. There are two pathophysiological phenomena currently used to describe the viable myocardium: myocardial stunning and hibernation. Myocardial stunning refers to the phenomenon of contractile dysfunction of the ischemic heart which persists for hours or weeks even after reperfusion, in which the recovery of myocardial function depends on the duration and severity of ischemia as well as rate of coronary blood flow. Myocardial hibernation refers to dysfunctional myocardium, which is in a state of metabolic downregulation resulting from sustained hypoperfusion. In these cases viable myocardium may take weeks or months to recover once flow is restored. One of the key differences between these two concepts is that resting myocardial perfusion is normal/near normal in stunning but is reduced in hibernation. Both conditions are reversible and hibernation could be considered as the summation of repetitive and cumulative stunning; they may contribute to LV dyssynchrony and heart failure in patients with CAD [67]. Currently, PET is regarded as the gold standard for viability assessment.

Generally, cardiac contraction requires energy generated by aerobic metabolic pathways; therefore, measurements of myocardial oxygen consumption would provide direct assessments of the myocardial oxidative metabolism. Noninvasive quantitative measurements of myocardial oxygen consumption in human can be made by PET imaging with $\left[{ }^{15} \mathrm{O}\right] \mathrm{O}_{2}$ inhalation. Iida et al. [68] described a kinetic model for quantification of regional myocardial oxygen consumption and oxygen extraction fraction and it is the first approach to allow direct quantitative determination of oxygen extraction fraction and oxygen metabolism to be made noninvasively on a regional basis. Yamamoto et al. [69] validated the method for noninvasive quantification of regional myocardial oxygen consumption and oxygen extraction fraction by PET with $\left[{ }^{15} \mathrm{O}\right] \mathrm{O}_{2}$ inhalation using three distinct analytical approaches, each of which provides accurate measurements of regional myocardial oxygen consumption and oxygen extraction fraction compared with invasive reference techniques. Major 
disadvantages of $\left[{ }^{15} \mathrm{O}\right] \mathrm{O}_{2}$ include the need for multiple tracers to calculate myocardial blood flow and blood volume and, due to its short physical half-life, requirement for an onsite cyclotron.

Acetate is a 2-carbon fatty acid (FA) that is rapidly pickedup by cells and metabolized into acetyl-CoA, which enters the tricarboxylic acid cycle. $\left[{ }^{11} \mathrm{C}\right]$ acetate has been proposed as a tracer of oxidative metabolism, with $\left[{ }^{11} \mathrm{C}\right]$ acetyl-CoA being rapidly converted into $\mathrm{CO}_{2}$ and water [70]. Brown et al. [71] were first to apply $\left[{ }^{11} \mathrm{C}\right]$ acetate to the study myocardial oxygen utilization in New Zealand rabbits and demonstrated that $\left[{ }^{11} \mathrm{C}\right]$ acetate has a high extraction fraction and rapid decline of blood pool radioactivity in vivo. Brown et al. [72] further demonstrated that the efflux of labeled $\mathrm{CO}_{2}$ after the administration of $\left[{ }^{11} \mathrm{C}\right]$ acetate reflects myocardial oxygen consumption $\left(\mathrm{MVO}_{2}\right)$ and that it is only minimally influenced by the changes in substrate utilization $(<4 \%)$. The initial uptake of $\left[{ }^{11} \mathrm{C}\right]$ acetate is dependent on myocardial blood flow and has a relatively high first-pass extraction in myocardial tissue. It has also been shown that $\left[{ }^{11} \mathrm{C}\right]$ acetate can be used to quantify MBF with good agreement to actual MBF [73]. In addition, $\left[{ }^{11} \mathrm{C}\right]$ acetate PET has been shown to have high sensitivity for detection of recurrent prostate cancer and metastases [74]. However, $\left[{ }^{11} \mathrm{C}\right]$ acetate availability is limited by the short half-life of ${ }^{11} \mathrm{C}$ which must be produced on-site.

The myocardium has a high rate of energy consumption for contractile function and relies on a variety of metabolic substrates, with most of the energy required for contraction coming from oxidation of FAs under normal conditions. However, there is a decrease in FA oxidation and increased glycolysis and glucose oxidation under conditions of ischemia [75]. Indeed, decreased FAs use and enhanced glucose use is the metabolic signature of the ischemic heart, and therefore PET imaging of myocardial metabolism focuses on FAs and glucose [76].

FAs are rapidly and avidly extracted by the heart, but uptake and subsequent metabolism are complex. Once activated to acyl-CoA, FAs can be degraded by $\beta$-oxidation in mitochondria. The transfer of acyl residues into the mitochondrial matrix relies on the carnitine-dependent transport system, which serves as the primary regulatory site for FA oxidation [77]. Ischemia results in insignificant loss of carnitine from the myocardium and accumulation of longchain acyl-carnitine and acyl-CoA [78]. [ $\left.{ }^{11} \mathrm{C}\right]$ palmitate, one of the earliest tracers developed, has been used extensively in imaging of the heart and can be used to evaluate the enzymatic activity of carnitine-palmitoyl transferase I [79]. Early studies have shown that the size of the defect identified by PET imaging after $\left[{ }^{11} \mathrm{C}\right]$ palmitate administration enabled quantification and localization of myocardial infarcts in patients [80]. There are large zones of intensely depressed accumulation of $\left[{ }^{11} \mathrm{C}\right]$ palmitate in patients with ischemic cardiomyopathy, suggesting that cardiomyopathic states are associated with alteration in FA metabolism [81]. However, the clinical use of $\left[{ }^{11} \mathrm{C}\right]$ palmitate has been limited by its complex kinetics and backdiffusion of the unmetabolized tracer from the myocytes, as well as its relatively complicated synthesis and need for an on-site cyclotron.
FA analogues act as false substrates or inhibitors of FA metabolism, and many PET FA analogue tracers have been designed to reflect myocardial $\beta$-oxidation. 14-(R,S)${ }^{18} \mathrm{~F}$-fluoro-6-thia-heptadecanoic acid ( $\left.\left[{ }^{18} \mathrm{~F}\right] \mathrm{FTHA}\right)$ is a longchain fatty acid analogue with a high first-pass uptake rate, which becomes trapped in the mitochondria after incomplete $\beta$-oxidation. Inhibition of FA oxidation resulted in $81-87 \%$ decrease in uptake of $\left[{ }^{18} \mathrm{~F}\right] \mathrm{FTHA}$ in rat heart, suggesting that accumulation of $\left[{ }^{18} \mathrm{~F}\right] \mathrm{FTHA}$ in the myocardium may be useful in assessment of the $\beta$-oxidation rate of long-chain FAs [82]. Although there is an increased myocardial FA uptake of $\left[{ }^{18} \mathrm{~F}\right]$ FTHA in patients with heart failure [83], studies have shown $\left[{ }^{18} \mathrm{~F}\right]$ FTHA to be insensitive to the inhibition of $\beta$ oxidation by hypoxia [84]. 16- $\left[{ }^{18} \mathrm{~F}\right]$ fluoro-4-thia-palmitate ( $\left.\left[{ }^{18} \mathrm{~F}\right] \mathrm{FTP}\right)$ was developed to improve sensitivity to the FA oxidation by hypoxia and was found to be capable of detecting the influence of exogenous long-chain FAs on myocardial oxidation rates. However, myocardial retention of $\left[{ }^{18} \mathrm{~F}\right] \mathrm{FTP}$ was suboptimal [85]. Furthermore, ${ }^{18}$ F-fluoro-4-thia-oleate $\left(\left[{ }^{18} \mathrm{~F}\right] \mathrm{FTO}\right)$ has been shown to have a higher myocardial retention and superior myocardial imaging compared to $\left[{ }^{18} \mathrm{~F}\right] \mathrm{FTP}$, as well as having many properties of a promising metabolically trapped FA oxidation tracer (Figure 3) [86].

FAs play a major role in the metabolism of the heart; however, glucose becomes the major substrate for the myocardium under ischemic conditions $[87,88]$.

${ }^{18} \mathrm{~F}$-fluorodeoxyglucose $\left[{ }^{18} \mathrm{~F}\right] \mathrm{FDG}$ is an analogue of glucose and is used to visualize glucose metabolism in vivo. $\left[{ }^{18} \mathrm{~F}\right]$ FDG is currently the most widely used PET tracer worldwide, particularly in oncology. $\left[{ }^{18} \mathrm{~F}\right] \mathrm{FDG}$ is taken up by myocytes via facilitated diffusion through a sarcolemmal glucose transporter, followed by phosphorylation by the hexokinase to $\left[{ }^{18} \mathrm{~F}\right]$ FDG-6-phosphate. After phosphorylation, the molecule is intracellularly trapped without undergoing further metabolism. As a result, $\left[{ }^{18} \mathrm{~F}\right] \mathrm{FDG}$ is effectively fixed in the myocardium in a manner that is proportional to the transport rate of glucose transporter and the activity of hexokinase. In cardiology, $\left[{ }^{18} \mathrm{~F}\right] \mathrm{FDG}$ has been approved for viability assessment with PET by FDA and can be considered the gold standard for detection of the reversibility of injured myocardium in the clinical setting [89].

Viable myocardium has a preserved or increased glucose utilization in hypoperfused and dysfunctional myocardium (flow-metabolism mismatch), whereas nonviable segments have a concordant reduction in both blood flow and FDG uptake (matched defect) [9]. In the fasting state, $\left[{ }^{18} \mathrm{~F}\right] \mathrm{FDG}$ myocardial uptake is low and heterogeneous. To maximize myocardial uptake, $\left[{ }^{18} \mathrm{~F}\right] \mathrm{FDG}$ is normally administrated after an oral glucose load or insulin clamp. Acipimox, which decreases serum FAs by inhibiting lipolysis and indirectly stimulates cardiac $\left[{ }^{18} \mathrm{~F}\right] \mathrm{FDG}$ uptake, is an alternative clamp option. This approach is able to produce good image quality in both clinic and research settings [90, 91]. The first-pass extraction fraction of $\left[{ }^{18} \mathrm{~F}\right] \mathrm{FDG}$ is not only high but also adequate for most studies. Based on regional uptake of $\left[{ }^{18} \mathrm{~F}\right] \mathrm{FDG}$, images are usually interpreted semiquantitatively. Knuuti et al. [92] found that absolute quantification of regional 

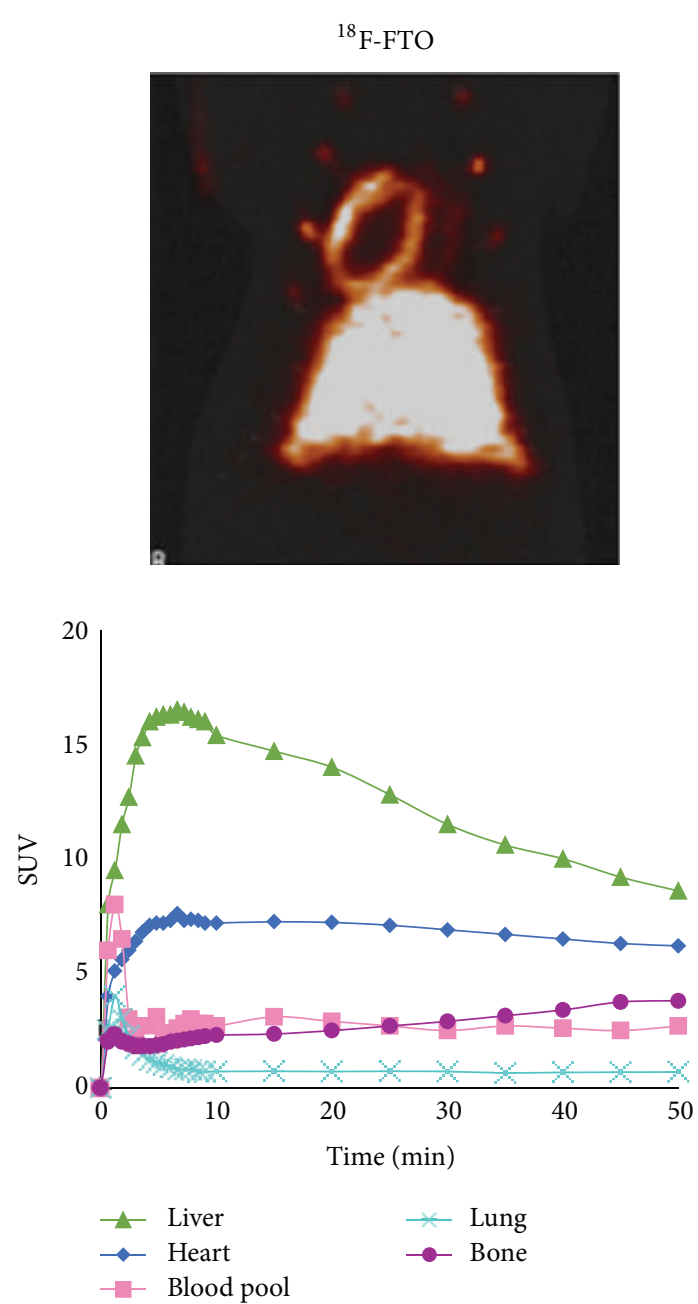
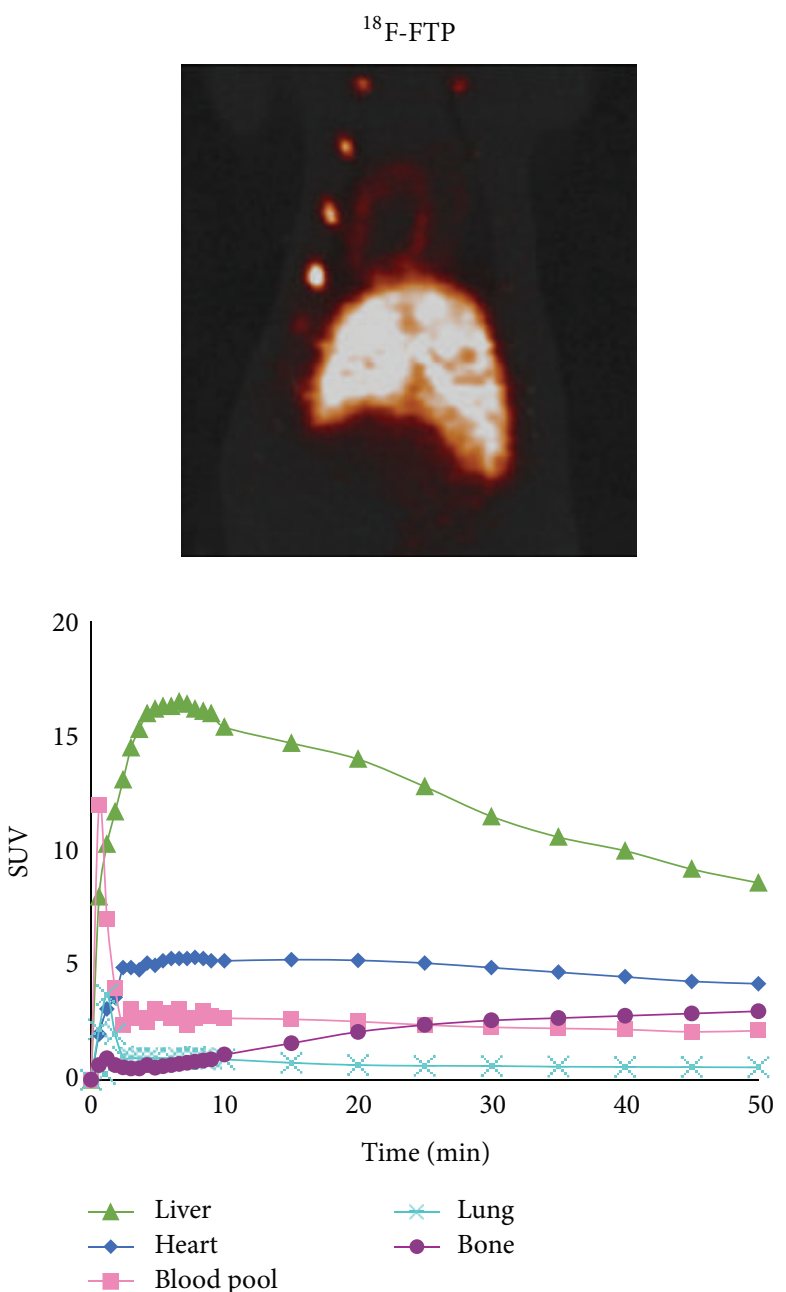

Figure 3: Early time-activity curves for ${ }^{18} \mathrm{~F}$-FTO and ${ }^{18} \mathrm{~F}$-FTP in rat heart (left ventricle), liver, lung, bone (rib), and blood pool and PET thoracic images acquired at 55-115 min after administration (from [86] with permission).

myocardial glucose utilization does not enhance the diagnostic accuracy of $\left[{ }^{18} \mathrm{~F}\right] \mathrm{FDG}$ PET for viable myocardium, likely due to larger variability of regional myocardial glucose utilization. In clinical practice, viable myocardium studies with $\left[{ }^{18} \mathrm{~F}\right] \mathrm{FDG}$ are usually combined with myocardial perfusion with $\left[{ }^{13} \mathrm{~N}\right] \mathrm{NH}_{3}$ or ${ }^{82} \mathrm{Rb}$. Cardiovascular metabolic imaging with $\left[{ }^{18} \mathrm{~F}\right] \mathrm{FDG}$ not only is limited to the assessment of myocardial viability, but also can be used to assess the severity of inflammation in carotid plaques [93].

\section{Other Biomarker-Based Probes}

Angiogenesis is the development of new capillaries from existing microvessels. Myocardial ischemia and infarctions result in hypoxia which stimulates angiogenesis [94]. Many factors have been found to contribute to the process of angiogenesis, and vascular endothelial growth factor (VEGF) is considered to be the most predominant factor [95]. In addition, integrins also participate in a number of processes related to angiogenesis [96], with $\alpha_{v} \beta_{3}$ being the most abundant integrin expressed on the surface of proliferating endothelial cells [97]. VEGF and $\alpha_{v} \beta_{3}$ integrin have been identified as favorable biomarkers for imaging angiogenesis using PET tracers for these targets [98, 99].

Many PET tracers have been developed for imaging of VEGF receptors in myocardial angiogenesis [100]. ${ }^{64} \mathrm{Cu}-$ DOTA-VEGF121 was developed for imaging VEGF receptor in a rat myocardial infarction model and provides a useful tool for study of CAD biology [101]. PET/CT with reporter gene technology has been used to identify expression of $\mathrm{VEGF}_{121}$ in myocardium of healthy pigs after regional adenoviral transfer of the $\mathrm{VEFG}_{121}$ gene, with results suggesting that this technology could lead to targeted therapeutic interventions with an imaging modality for assessment of the clinical usefulness of therapy [102].

There has been significant focus on imaging of the $\alpha_{v} \beta_{3}$ integrin with the RGD (Arg-Gly-Asp) motif. The RGD peptides, which were identified by in vivo screening of phage-display peptide libraries, have high affinities for the $\alpha_{v} \beta_{3}$ integrin. PET with ${ }^{18}$ F-AlF-NOTA-PRGD2 allows noninvasive visualization of ischemia/reperfusion-induced myocardial angiogenesis longitudinally, and its favorable 


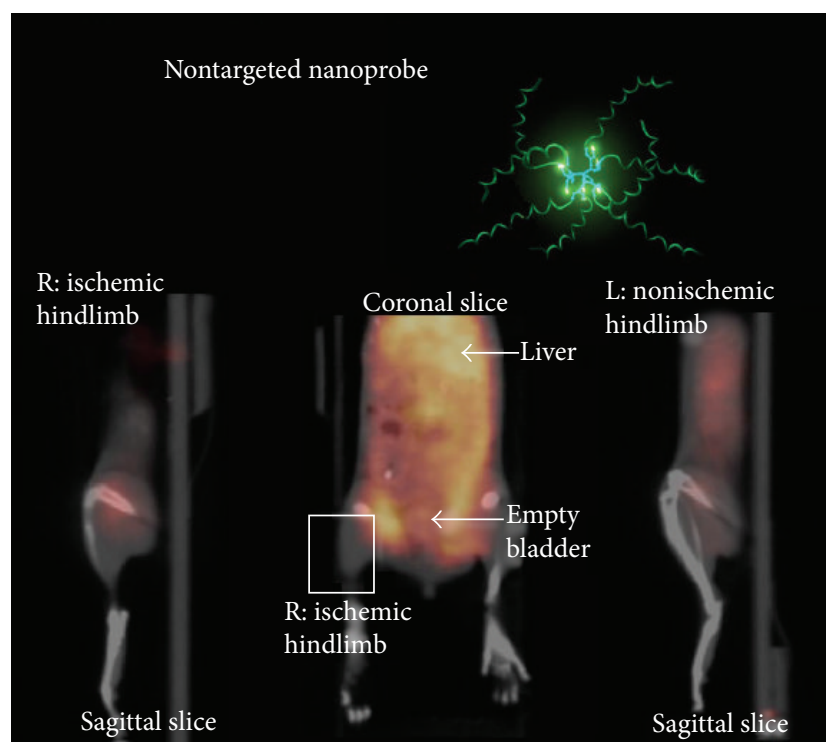

(a)

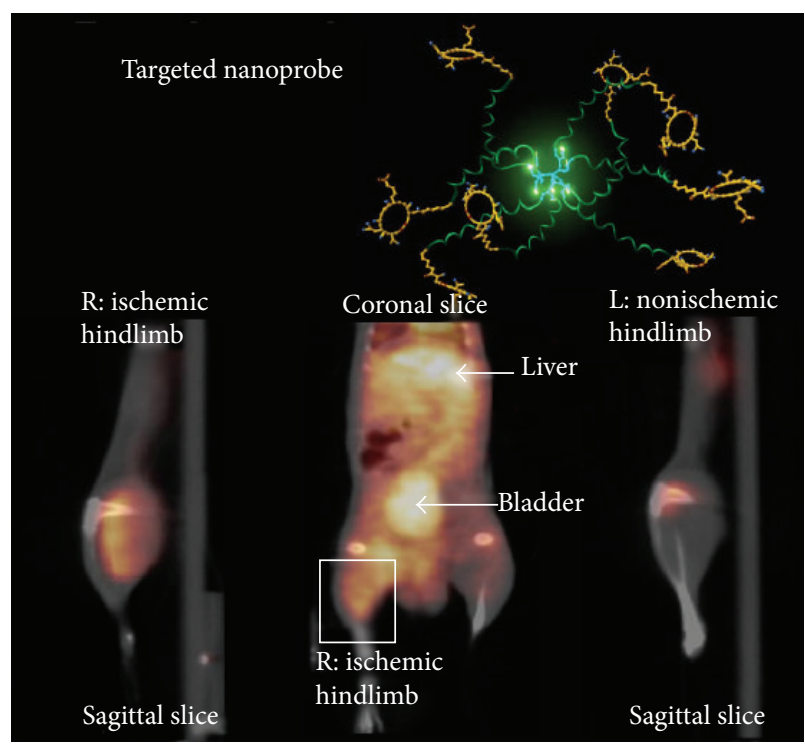

(b)

FIgURE 4: Noninvasive PET/CT images of angiogenesis induced by hindlimb ischemia in a murine model. Uptake of targeted dendritic nanoprobes was higher in ischemic hindlimb (a) as compared with control hindlimb (b) (from [106] with permission).

pharmacokinetics and easy production should facilitate its future clinical translation for lesion evaluation and therapy response monitoring in patients with occlusive cardiovascular diseases [103]. $\left[{ }^{18} \mathrm{~F}\right]$ Galacto-RGD allows quantification of $\alpha_{v} \beta_{3}$ expression in vivo and has been successfully used to image angiogenesis in a patient 2 weeks after myocardial infarction $[104,105]$. A biodegradable dendritic PET imaging nanoprobe developed by Almutairi et al. [106] has been shown to have enhanced bioavailability, in vivo radiostability, and increased binding specificity to $\alpha_{\nu} \beta_{3}$ integrin (Figure 4). In addition, this nanoprobe may allow for targeted drug delivery, potentially providing an approach for translation of novel theranostic tracers into clinical practice.

The $\beta$-adrenoceptor ( $\beta$-AR) plays an important role in heart failure, with low $\beta$-AR density a direct reflection of decreased contractility in the heart, an important hallmark of heart failure. Although, clinical studies have demonstrated heart failure, patients could benefit from $\beta$-blocker therapy [107], it remains difficult to predict whether heart failure patients will respond favorably to $\beta$-blockers. De Jong et al. $[108]$ have demonstrated that $(S)-\left[{ }^{11} \mathrm{C}\right] \mathrm{CGP} 12388$ can be used to directly measure myocardial $\beta$-AR density in patients, revealing a significant reduction of $\beta$-AR density in patients with idiopathic dilated cardiomyopathy. While Naya et al. [109] have demonstrated that PET with ${ }^{11}$ C-CGP12177 can predict the improvement of cardiac function in patients with idiopathic dilated cardiomyopathy (IDC) after long-term carvedilol treatment.

Sympathetic nerves play key roles in cardiac physiology and aging-related cardiovascular diseases. Most of the norepinephrine in the human heart is removed by neuronal uptake [110] and studies have suggested that decreased neuronal uptake activity may contribute to congestive heart failure [111]. $6-\left[{ }^{18} \mathrm{~F}\right]$ fluopamine is an analogue of dopamine that has a similar metabolic fate to that of endogenous catecholamines. $6-\left[{ }^{18} \mathrm{~F}\right]$ fluopamine not only could assess sympathetic innervation and function in the heart, but can also detect altered cardiac uptake of catecholamines activity $[112,113]$.

Sympathetic nerves are exquisitely sensitive to ischemia [114], and regional cardiac sympathetic nerve dysfunction might have a role in its association with sudden cardiac death. ${ }^{11} \mathrm{C}$-hydroxyephedrine $\left(\left[{ }^{11} \mathrm{C}\right] \mathrm{HED}\right)$ is a norepinephrine analogue that can be used for the noninvasive evaluation of neuronal integrity using PET. Studies have demonstrated profound reductions in regional uptake of norepinephrine by sympathetic nerves with $\left[{ }^{11} \mathrm{C}\right] \mathrm{HED}$ imaging in a porcine model of hibernating myocardium [115]. However, PET imaging with $\left[{ }^{11} \mathrm{C}\right] \mathrm{HED}$ cannot accurately quantify regional nerve densities due to the rapid neuronal uptake rates. Raffel et al. [116] recently synthesized $\mathrm{N}^{11}{ }^{11} \mathrm{C}$-guanyl-(-)-metaoctopamine $\left(\left[{ }^{11} \mathrm{C}\right] \mathrm{GMO}\right)$, which has a much slower NET transport rate and is trapped in storage vesicles. Initial results have shown that $\left[{ }^{11} \mathrm{C}\right] \mathrm{GMO}$ provides robust and sensitive quantitative measurements of regional cardiac sympathetic nerve density and might be able to detect mild-to-moderate sympathetic nerve loss at the early stages of cardiac denervation.

\section{PET/MRI Dual Functional Probes}

Nuclear medicine imaging, and PET in particular, has a significant role in both increasing understanding of the mechanisms of cardiovascular disease and in improving patient diagnostic accuracy. However, no single modality is perfect and sufficient to provide physicians with all the necessary 


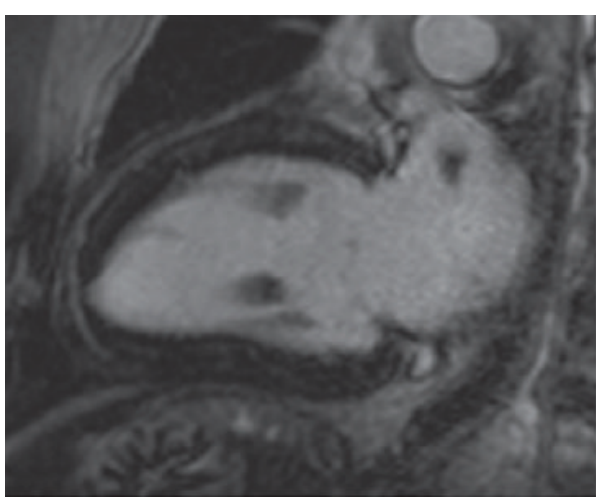

(a)

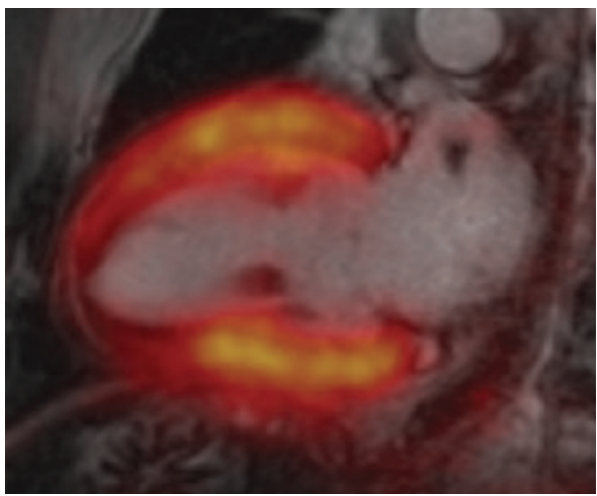

(b)

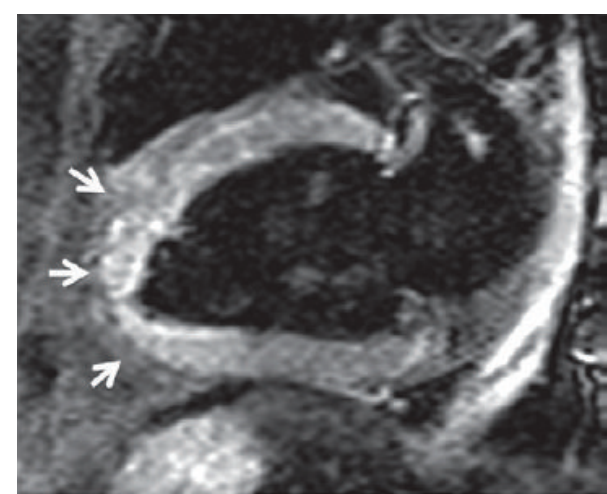

(c)

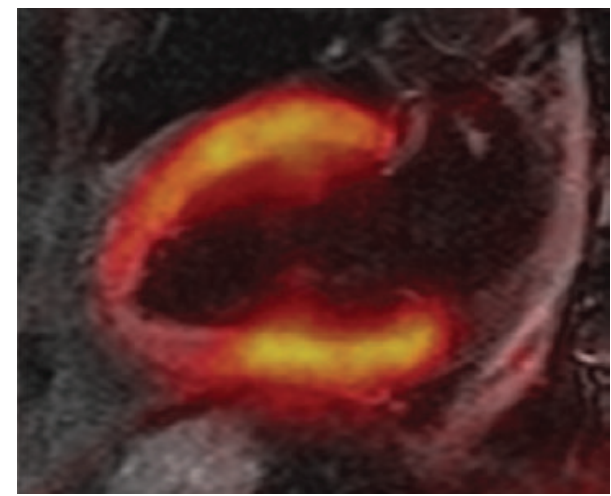

(d)

FIGURE 5: Cardiac PET/MR imaging of a 66-year-old male patient with ST-elevation myocardial infarction and acute occlusion of the left anterior descending artery. (a) Late gadolinium-enhanced (LGE) image shows no infarction zone. (b) Fused LGE and PET images show that tracer uptake was reduced. (c) MR image shows myocardial edema (arrows) that corresponded well with the area of reduced tracer uptake on (d) (from [118] with permission).

information. By combining new tracers with multimodalityimaging instruments that merge structural information and functional data, physicians can perform multiple functionalimaging assays simultaneously with anatomic analyses [117]. Cardiac PET/CT has been used in a variety of clinical scenarios and quantitative measurements of MBF may further enhance its diagnostic performance.

The combination of PET and MRI is another widely studied multimodality imaging technique, potentially providing opportunity for improved understanding of the mechanism and diagnosis of cardiovascular diseases. Nensa et al. [118] have demonstrated the feasibility of hybrid cardiac imaging with an integrated whole body 3-T PET/MRI that produced high-quality cardiac MR imaging acquisitions (Figure 5). MRI could provide exact anatomical localization and volume correction for detection and quantification of molecular targets by PET, with other major advantages of PET/MRI over PET/CT including the reduction of radiation dose. With its improved tissue characterization PET/MRI has potential for atherosclerotic plaque imaging and assessment of myocardial viability/hibernation. For example, PET/MRI opens opportunities to combine anatomy (plaque burden) with haemodynamic consequences (ischaemia) of CAD [119].

Although clinical applications of such technology are still under debate, a few multifunctional probes for PET/MRI systems have already been developed for future diagnostic applications. Jerrett et al. [120] have developed dual-mode $\mathrm{PET} / \mathrm{MRI}$ probes targeted to vascular inflammation, such as atherosclerosis. The probe was synthesized by coordination of the ${ }^{64} \mathrm{Cu}$ to the chelating bifunctional ligand $S$-2-(4-isothiocyanatobenzyl)-1,4,7,10-tetraazacyclododecane-1,4,7,10tetraacetic acid ( $p$-SCN-Bz-DOTA) and then conjugated to the dextran sulfate coated iron oxide nanoparticle. In addition, Lee et al. [121] recently developed an iron oxide nanoparticle-based tracer for PET/MR imaging of integrin $\alpha_{v} \beta_{3}$ expression. Poly(aspartic acid)-coated iron oxide nanoparticles (PASP-IO) were synthesized, and the surface amino groups were coupled to cyclic RGD peptides and DOTA chelators for integrin $\alpha_{v} \beta_{3}$ targeting and PET imaging (after labeling with ${ }^{64} \mathrm{Cu}$ ), respectively. The success of this approach may allow for accurate early diagnosis of angiogenesis as well as providing molecular information specific to the disease of interest.

The future of PET/MRI is likely to benefit from the use of dual-modality PET/MRI imaging probes. However, the problem of differences in sensitivities between the two modalities remains to be solved. PET is a highly sensitive imaging modality that requires only a trace amount of probes (nanograms), whereas MRI requires a relatively high amount of contrast agent (micrograms to milligrams) [4]. Thus, the 
detection sensitivities for different imaging modalities should be further considered and optimized. With the improvement in PET/MRI fusion and the development of novel MRI systems with much improved sensitivity, dual-modality PETMRI imaging agents will surely shed new light on molecular imaging of cardiovascular disease.

\section{Conclusion}

Boosted by advances in molecular biology, biotechnology, and chemistry imaging techniques, cardiovascular molecular imaging has grown rapidly in the last decade. The commonly used tracers for the noninvasive imaging of cardiovascular disease are becoming important in the paradigm shift from traditional to future imaging technologies, offering unique opportunities for improved understanding of cardiovascular disease pathogenesis and progression, and ultimately helping to optimize therapeutic interventions in patients suffering from cardiovascular disease. The development of new PET tracers that possess imaging, targeting, and therapeutic functions will remain key elements of future research in the field of cardiac PET, which will be a useful tool to monitoring new therapeutic strategies in the battle against cardiovascular disease.

\section{Conflict of Interests}

The authors declare that there is no conflict of interests regarding the publication of this paper.

\section{Authors' Contribution}

Yesen Li and Wei Zhang contributed equally to this work.

\section{Acknowledgments}

This work was project supported by the National Natural Science Foundation of China (NSFC) (Grant nos. 81101101 and 81371596), the Key Project of Chinese Ministry of Education (Grant no. 212149), and the Projects of Sichuan Province (Grant nos. 2010SZ0294, 2011JQ0032, and 12ZB038), and the Fundamental Research Funds for the Central Universities, China (Grant no. 2013121039).

\section{References}

[1] H. Oxenham and N. Sharpe, "Cardiovascular aging and heart failure," European Journal of Heart Failure, vol. 5, no. 4, pp. 427434, 2003.

[2] O. Gaemperli and P. A. Kaufmann, "PET and PET/CT in cardiovascular disease," Annals of the New York Academy of Sciences, vol. 1228, no. 1, pp. 109-136, 2011.

[3] M. Schwaiger, S. I. Ziegler, and S. G. Nekolla, "PET/CT challenge for the non-invasive diagnosis of coronary artery disease," European Journal of Radiology, vol. 73, no. 3, pp. 494-503, 2010.

[4] T. F. Massoud and S. S. Gambhir, "Molecular imaging in living subjects: seeing fundamental biological processes in a new light," Genes and Development, vol. 17, no. 5, pp. 545-580, 2003.
[5] L. W. Dobrucki and A. J. Sinusas, "PET and SPECT in cardiovascular molecular imaging," Nature Reviews Cardiology, vol. 7, no. 1, pp. 38-47, 2010.

[6] B. Jang, S. Park, S. H. Kang et al., "Gold nanorods for target selective SPECT/CT imaging and photothermal therapy in vivo," Quantitative Imaging in Medicine and Surgery, vol. 2, pp. 1-11, 2012.

[7] F. J. Klocke, M. G. Baird, B. H. Lorell et al., "ACC/AHA/ASNC guidelines for the clinical use of cardiac radionuclide imagingexecutive summary: a report of the American College of Cardiology/American Heart Association Task Force on Practice Guidelines (ACC/AHA/ASNC Committee to Revise the 1995 Guidelines for the Clinical Use of Cardiac Radionuclide Imaging)," Journal of the American College of Cardiology, vol. 42, no. 7, pp. 1318-1333, 2003.

[8] M. M. Ter Pogossian, M. E. Phelps, E. J. Hoffman, and N. A. Mullan, "A positron emission transaxial tomograph for nuclear imaging (PETT)," Radiology, vol. 114, no. 1, pp. 89-98, 1975.

[9] R. H. J. A. Slart, J. J. Bax, D. J. van Veldhuisen, E. E. van der Wall, R. A. J. O. Dierckx, and P. L. Jager, "Imaging techniques in nuclear cardiology for the assessment of myocardial viability," International Journal of Cardiovascular Imaging, vol. 22, no. 1, pp. 63-80, 2006.

[10] S. M. Ametamey, M. Honer, and P. A. Schubiger, "Molecular imaging with PET," Chemical Reviews, vol. 108, no. 5, pp. 15011516, 2008.

[11] A. R. Kherlopian, T. Song, Q. Duan et al., "A review of imaging techniques for systems biology," BMC Systems Biology, vol. 2, article 74, 2008.

[12] S. Dorbala, M. F. Di Carli, R. S. Beanlands et al., "Prognostic value of stress myocardial perfusion positron emission tomography: results from a multicenter observational registry," Journal of the American College of Cardiology, vol. 61, no. 2, pp. 176184, 2013.

[13] M. Kobylecka, J. Maçzewska, K. Fronczewska-Wieniawska, T. Mazurek, M. T. Płazińska, and L. Królicki, "Myocardial viability assessment in 18FDG PET/CT study (18FDG PET myocardial viability assessment)," Nuclear Medicine Review, vol. 15, no. 1, pp. 52-60, 2012.

[14] S. R. Underwood, P. de Bondt, A. Flotats et al., "The current and future status of nuclear cardiology: a consensus report," European Heart Journal Cardiovascular Imaging, 2014.

[15] I. Danad, P. G. Raijmakers, and P. Knaapen, "Diagnosing coronary artery disease with hybrid PET/CT: it takes two to tango," Journal of Nuclear Cardiology, vol. 20, no. 5, pp. 874-890, 2013.

[16] A. Flotats, J. Knuuti, M. Gutberlet et al., "Hybrid cardiac imaging: SPECT/CT and PET/CT. A joint position statement by the European Association of Nuclear Medicine (EANM), the European Society of Cardiac Radiology (ESCR) and the European Council of Nuclear Cardiology (ECNC)," European Journal of Nuclear Medicine and Molecular Imaging, vol. 38, no. 1, pp. 201-212, 2011.

[17] O. Ratib and R. Nkoulou, "Potential applications of PET/MR imaging in cardiology," Journal of Nuclear Medicine, vol. 55, pp. 40S-46S, 2014.

[18] O. O. Sogbein, M. Pelletier-Galarneau, T. H. Schindler, L. Wei, R. G. Wells, and T. D. Ruddy, "New SPECT and PET radiopharmaceuticals for imaging cardiovascular disease," BioMed Research International, vol. 2014, Article ID 942960, 25 pages, 2014. 
[19] A. Rahmim and H. Zaidi, "PET versus SPECT: strengths, limitations and challenges," Nuclear Medicine Communications, vol. 29, no. 3, pp. 193-207, 2008.

[20] G. S. Thomas and J. Maddahi, "The technetium shortage," Journal of Nuclear Cardiology, vol. 17, no. 6, pp. 993-998, 2010.

[21] B. J. Pichler, H. F. Wehrl, and M. S. Judenhofer, "Latest advances in molecular imaging instrumentation," Journal of Nuclear Medicine, vol. 49, supplement 2, pp. 5S-23S, 2008.

[22] J. Patton, M. Sandler, D. Berman et al., "D-SPECT: a new solid state camera for high speed molecular imaging," The Journal of Nuclear Medicine, vol. 47, supplement 1, p. 189, 2006.

[23] P. Koepfli, T. F. Hany, C. A. Wyss et al., "CT attenuation correction for myocardial perfusion quantification using a PET/CT hybrid scanner," Journal of Nuclear Medicine, vol. 45, no. 4, pp. 537-542, 2004.

[24] C. Anagnostopoulos, A. Georgakopoulos, N. Pianou, and S. G. Nekolla, "Assessment of myocardial perfusion and viability by positron emission tomography," International Journal of Cardiology, vol. 167, no. 5, pp. 1737-1749, 2013.

[25] J. L. G. C. Filho, R. de Souza Leão Lima, L. de Souza MacHado Neto, L. Kayat Bittencourt, R. C. Domingues, and L. M. B. Da Fonseca, "PET/CT and vascular disease: current concepts," European Journal of Radiology, vol. 80, no. 1, pp. 60-67, 2011.

[26] K. Knešaurek, J. Machac, and J. Ho Kim, "Comparison of 2D, $3 \mathrm{D}$ high dose and 3D low dose gated myocardial 82Rb PET imaging," BMC Nuclear Medicine, vol. 7, article 4, 2007.

[27] K. Knešaurek, J. Machac, B. R. Krynyckyi, and O. D. Almeida, "Comparison of 2-dimensional and 3-dimensional 82Rb myocardial perfusion PET imaging," Journal of Nuclear Medicine, vol. 44, no. 8, pp. 1350-1356, 2003.

[28] A. Sánchez-Crespo, P. Andreo, and S. A. Larsson, "Positron flight in human tissues and its influence on PET image spatial resolution," European Journal of Nuclear Medicine and Molecular Imaging, vol. 31, no. 1, pp. 44-51, 2004.

[29] P. A. Kaufmann, T. Gnecchi-Ruscone, J. T. Yap, O. Rimoldi, and P. G. Camici, "Assessment of the reproducibility of baseline and hyperemic myocardial blood flow measurements with 15Olabeled water and PET," Journal of Nuclear Medicine, vol. 40, no. 11, pp. 1848-1856, 1999.

[30] D. K. Glover and R. J. Gropler, "Journey to find the ideal PET flow tracer for clinical use: are we there yet?" Journal of Nuclear Cardiology, vol. 14, no. 6, pp. 765-768, 2007.

[31] H. Iida, I. Kanno, A. Takahashi et al., "Measurement of absolute myocardial blood flow with $\mathrm{H} 215 \mathrm{O}$ and dynamic positronemission tomography. Strategy for quantification in relation to the partial-volume effect," Circulation, vol. 78, no. 1, pp. 104-115, 1988.

[32] E. U. Nitzsche, Y. Choi, J. Czernin, C. K. Hoh, S. Huang, and H. R. Schelbert, "Noninvasive quantification of myocardial blood flow in humans: a direct comparison of the $\left[{ }^{13} \mathrm{~N}\right]$ ammonia and the $\left[{ }^{15} \mathrm{O}\right]$ water techniques," Circulation, vol. 93 , no. 11, pp. $2000-$ 2006, 1996.

[33] C. Katoh, K. Morita, T. Shiga, N. Kubo, K. Nakada, and N. Tamaki, "Improvement of algorithm for quantification of regional myocardial blood flow using $15 \mathrm{O}$-water with PET," Journal of Nuclear Medicine, vol. 45, no. 11, pp. 1908-1916, 2004.

[34] H. J. Harms, P. Knaapen, S. De Haan, R. Halbmeijer, A. A. Lammertsma, and M. Lubberink, "Automatic generation of absolute myocardial blood flow images using $\left[{ }^{15} \mathrm{O}\right] \mathrm{H}_{2} \mathrm{O}$ and a clinical PET/CT scanner," European Journal of Nuclear Medicine and Molecular Imaging, vol. 38, no. 5, pp. 930-939, 2011.
[35] I. Adachi, O. Gaemperli, I. Valenta et al., "Assessment of myocardial perfusion by dynamic O-15-labeled water PET imaging: validation of a new fast factor analysis," Journal of Nuclear Cardiology, vol. 14, no. 5, pp. 698-705, 2007.

[36] M. F. Di Carli, S. Dorbala, J. Meserve, G. El Fakhri, A. Sitek, and S. C. Moore, "Clinical myocardial perfusion PET/CT," Journal of Nuclear Medicine, vol. 48, no. 5, pp. 783-793, 2007.

[37] H. J. Harms, S. De Haan, P. Knaapen, C. P. Allaart, A. A. Lammertsma, and M. Lubberink, "Parametric images of myocardial viability using a single ${ }^{15} \mathrm{O}-\mathrm{H}_{2} \mathrm{O}$ PET/CT scan," Journal of Nuclear Medicine, vol. 52, no. 5, pp. 745-749, 2011.

[38] T. M. Bateman, G. V. Heller, A. I. McGhie et al., "Diagnostic accuracy of rest/stress ECG-gated Rb-82 myocardial perfusion PET: comparison with ECG-gated Tc-99m sestamibi SPECT," Journal of Nuclear Cardiology, vol. 13, no. 1, pp. 24-33, 2006.

[39] R. T. Go, T. H. Marwick, W. J. MacIntyre et al., "A prospective comparison of rubidium-82 PET and thallium-201 SPECT myocardial perfusion imaging utilizing a single dipyridamole stress in the diagnosis of coronary artery disease," Journal of Nuclear Medicine, vol. 31, no. 12, pp. 1899-1905, 1990.

[40] J. Kim, P. E. Bravo, A. Gholamrezanezhad et al., "Coronary artery and thoracic aorta calcification is inversely related to coronary flow reserve as measured by $82 \mathrm{Rb} \mathrm{PET} / \mathrm{CT}$ in intermediate risk patients," Journal of Nuclear Cardiology, vol. 20, no. 3, pp. 375-384, 2013.

[41] G. V. Heller, D. Calnon, and S. Dorbala, "Recent advances in cardiac PET and PET/CT myocardial perfusion imaging," Journal of Nuclear Cardiology, vol. 16, no. 6, pp. 962-969, 2009.

[42] S. Senthamizhchelvan, P. E. Bravo, C. Esaias et al., "Human biodistribution and radiation dosimetry of $82 \mathrm{Rb}$," Journal of Nuclear Medicine, vol. 51, no. 10, pp. 1592-1599, 2010.

[43] P. Arumugam, D. Tout, and C. Tonge, "Myocardial perfusion scintigraphy using rubidium-82 positron emission tomography," British Medical Bulletin, vol. 107, pp. 87-100, 2013.

[44] R. Lautamäki, R. T. George, K. Kitagawa et al., "Rubidium-82 PET-CT for quantitative assessment of myocardial blood flow: validation in a canine model of coronary artery stenosis," European Journal of Nuclear Medicine and Molecular Imaging, vol. 36, no. 4, pp. 576-586, 2009.

[45] R. A. Goldstein, N. A. Mullani, S. K. Marani, D. J. Fisher, K. L. Gould, and H. A. O'Brien Jr., "Myocardial perfusion with rubidium-82. II. Effects of metabolic and pharmacologic interventions," Journal of Nuclear Medicine, vol. 24, no. 10, pp. 907915, 1983.

[46] J. Krivokapich, S. C. Huang, M. E. Phelps, N. S. MacDonald, and K. I. Shine, "Dependence of $13 \mathrm{NH} 3$ myocardial extraction and clearance on flow and metabolism," The American Journal of Physiology, vol. 242, no. 4, pp. H536-H542, 1982.

[47] H. R. Schelbert, M. E. Phelps, S. C. Huang et al., "N-13 ammonia as an indicator of myocardial blood flow," Circulation, vol. 63, no. 6, pp. 1259-1272, 1981.

[48] Y. Choi, S. C. Huang, R. A. Hawkins et al., "Quantification of myocardial blood flow using ${ }^{13} \mathrm{~N}$-ammonia and PET: comparison of tracer models," Journal of Nuclear Medicine, vol. 40, no. 6, pp. 1045-1055, 1999.

[49] B. A. Herzog, L. Husmann, I. Valenta et al., "Long-term prognostic value of $13 \mathrm{~N}$-ammonia myocardial perfusion positron emission tomography added value of coronary flow reserve," Journal of the American College of Cardiology, vol. 54, no. 2, pp. 150-156, 2009.

[50] M. Fiechter, C. Gebhard, J. R. Ghadri et al., "Myocardial perfusion imaging with $13 \mathrm{~N}$-Ammonia PET is a strong predictor for 
outcome," International Journal of Cardiology, vol. 167, no. 3, pp. 1023-1026, 2013.

[51] E. Alexánderson, R. Jácome, M. Jiménez-Santos et al., "Evaluation of the endothelial function in hypertensive patients with $13 \mathrm{~N}$-ammonia PET," Journal of Nuclear Cardiology, vol. 19, no. 5, pp. 979-986, 2012.

[52] M. Fiechter, J. R. Ghadri, C. Gebhard et al., "Diagnostic value of $13 \mathrm{~N}$-ammonia myocardial perfusion PET: added value of myocardial flow reserve," Journal of Nuclear Medicine, vol. 53, no. 8, pp. 1230-1234, 2012.

[53] B. Rauch, F. Helus, and M. Grunze, "Kinetics of ${ }^{13} \mathrm{~N}$-ammonia uptake in myocardial single cells indicating potential limitations in its applicability as a marker of myocardial blood flow," Circulation, vol. 71, no. 2, pp. 387-393, 1985.

[54] P. Yalamanchili, E. Wexler, M. Hayes et al., "Mechanism of uptake and retention of F-18 BMS-747158-02 in cardiomyocytes: a novel PET myocardial imaging agent," Journal of Nuclear Cardiology, vol. 14, no. 6, pp. 782-788, 2007.

[55] F. Schuler and J. E. Casida, "The insecticide target in the PSST subunit of complex I," Pest Management Science, vol. 57, no. 10, pp. 932-940, 2001.

[56] M. C. Huisman, T. Higuchi, S. Reder et al., "Initial characterization of an 18F-labeled myocardial perfusion tracer," Journal of Nuclear Medicine, vol. 49, no. 4, pp. 630-636, 2008.

[57] J. Maddahi, "Properties of an ideal PET perfusion tracer: new PET tracer cases and data," Journal of Nuclear Cardiology, vol. 19, supplement 1, pp. S30-S37, 2012.

[58] T. Higuchi, S. G. Nekolla, M. M. Huisman et al., "A new 18F-labeled myocardial PET tracer: myocardial uptake after permanent and transient coronary occlusion in rats," Journal of Nuclear Medicine, vol. 49, no. 10, pp. 1715-1722, 2008.

[59] J. Maddahi, J. Czernin, J. Lazewatsky et al., "Phase I, firstin-human study of BMS747158, a novel ${ }^{18} \mathrm{~F}$-labeled tracer for myocardial perfusion PET: dosimetry, biodistribution, safety, and imaging characteristics after a single injection at rest," Journal of Nuclear Medicine, vol. 52, no. 9, pp. 1490-1498, 2011.

[60] D. S. Berman, J. Maddahi, B. K. Tamarappoo et al., "Phase II safety and clinical comparison with single-photon emission computed tomography myocardial perfusion imaging for detection of coronary artery disease: flurpiridaz $\mathrm{F} 18$ positron emission tomography," Journal of the American College of Cardiology, vol. 61, no. 4, pp. 469-477, 2013.

[61] M. Yu, M. Guaraldi, M. Kagan et al., "Assessment of ${ }^{18}$ F-labeled mitochondrial complex I inhibitors as PET myocardial perfusion imaging agents in rats, rabbits, and primates," European Journal of Nuclear Medicine and Molecular Imaging, vol. 36, no. 1, pp. 63-72, 2009.

[62] T. Mou, H. Jing, W. Yang et al., "Preparation and biodistribution of $\left[{ }^{18} \mathrm{~F}\right] \mathrm{FP} 2 \mathrm{OP}$ as myocardial perfusion imaging agent for positron emission tomography," Bioorganic and Medicinal Chemistry, vol. 18, no. 3, pp. 1312-1320, 2010.

[63] I. Madar, H. T. Ravert, Y. Du et al., "Characterization of uptake of the new PET imaging compound ${ }^{18}$ F-fluorobenzyl triphenyl phosphonium in dog myocardium," Journal of Nuclear Medicine, vol. 47, no. 8, pp. 1359-1366, 2006.

[64] T. M. Shoup, D. R. Elmaleh, A. Brownell, A. Zhu, J. L. Guerrero, and A. J. Fischman, "Evaluation of $\left(4-\left[{ }^{18} \mathrm{~F}\right]\right.$ Fluorophenyl)triphenylphosphonium ion. A potential myocardial blood flow agent for PET," Molecular Imaging and Biology, vol. 13, no. 3, pp. 511517, 2011.

[65] E. Tadamura, N. Tamaki, H. Okazawa et al., "Generatorproduced copper-62-PTSM as a myocardial PET perfusion tracer compared with nitrogen-13-ammonia," Journal of Nuclear Medicine, vol. 37, no. 5, pp. 729-735, 1996.

[66] A. F. L. Schinkel, R. Valkema, M. L. Geleijnse, E. J. Sijbrands, and D. Poldermans, "Single-photon emission computed tomography for assessment of myocardial viability," EuroIntervention, vol. 6, supplement G, pp. G115-G122, 2010.

[67] A. Shabana and A. El-Menyar, "Myocardial viability: what we knew and what is new," Cardiology Research and Practice, vol. 1, no. 1, Article ID 607486, 2012.

[68] H. Iida, C. G. Rhodes, L. I. Araujo et al., "Noninvasive quantification of regional myocardial metabolic rate for oxygen by use of $15 \mathrm{O} 2$ inhalation and positron emission tomography: theory, error analysis, and application in humans," Circulation, vol. 94, no. 4, pp. 792-807, 1996.

[69] Y. Yamamoto, R. de Silva, C. G. Rhodes et al., "Noninvasive quantification of regional myocardial metabolic rate of oxygen by ${ }^{15} \mathrm{O}_{2}$ inhalation and positron emission tomography: experimental validation," Circulation, vol. 94, no. 4, pp. 808-816, 1996.

[70] I. Grassi, C. Nanni, V. Allegri et al., "The clinical use of PET with (11)C-acetate," American Journal of Nuclear Medicine and Molecular Imaging, vol. 2, pp. 33-47, 2012.

[71] M. Brown, D. R. Marshall, B. E. Sobel, and S. R. Bergmann, "Delineation of myocardial oxygen utilization with carbon-11labeled acetate," Circulation, vol. 76, no. 3, pp. 687-696, 1987.

[72] M. A. Brown, D. W. Myears, and S. R. Bergmann, "Validity of estimates of myocardial oxidative metabolism with carbon-11 acetate and positron emission tomography desite altered patterns of substrate utilization," Journal of Nuclear Medicine, vol. 30, no. 2, pp. 187-193, 1989.

[73] S. A. J. Timmer, M. Lubberink, T. Germans et al., "Potential of $\left[{ }^{11} \mathrm{C}\right]$ acetate for measuring myocardial blood flow: studies in normal subjects and patients with hypertrophic cardiomyopathy," Journal of Nuclear Cardiology, vol. 17, no. 2, pp. 264-275, 2010.

[74] K. Leung, “[ $\left.{ }^{11} \mathrm{C}\right]$ Acetate," 2004.

[75] W. C. Stanley, F. A. Recchia, and G. D. Lopaschuk, "Myocardial substrate metabolism in the normal and failing heart," Physiological Reviews, vol. 85, no. 3, pp. 1093-1129, 2005.

[76] S. R. Bergmann, "Imaging of myocardial fatty acid metabolism with PET," Journal of Nuclear Cardiology, vol. 14, no. 3, pp. S118S124, 2007.

[77] D. R. Bielefeld, T. C. Vary, and J. R. Neely, "Inhibition of carnitine palmitoyl-CoA transferase activity and fatty acid oxidation by lactate and oxfenicine in cardiac muscle," Journal of Molecular and Cellular Cardiology, vol. 17, no. 6, pp. 619-625, 1985.

[78] G. L. Bartels, W. J. Remme, and H. R. Scholte, "Acute myocardial ischaemia induces cardiac carnitine release in man," European Heart Journal, vol. 18, no. 1, pp. 84-90, 1997.

[79] G. Angsten, S. Valind, R. Takalo, H. Neu, S. Meurling, and B. Långström, "Inhibition of carnitine-acyl transferase I by oxfenicine studied in vivo with $\left[{ }^{11} \mathrm{C}\right]$-labeled fatty acids," Nuclear Medicine and Biology, vol. 32, no. 5, pp. 495-503, 2005.

[80] M. M. Ter-Pogossian, M. S. Klein, J. Markham, R. Roberts, and B. E. Sobel, "Regional assessment of myocardial metabolic integrity in vivo by position-emission tomography with ${ }^{11} \mathrm{C}$ labeled palmitate," Circulation, vol. 61, no. 2, pp. 242-255, 1980.

[81] E. M. Geltman, "Metabolic imaging of patients with cardiomyopathy," Circulation, vol. 84, no. 3, pp. I265-I272, 1991.

[82] T. R. DeGrado, H. H. Coenen, and G. Stocklin, "14(R,S)[18F]Fluoro-6-thia-heptadecanoic acid (FTHA): evaluation in 
mouse of a new probe of myocardial utilization of long chain fatty acids," Journal of Nuclear Medicine, vol. 32, no. 10, pp. 18881896, 1991.

[83] M. Taylor, T. R. Wallhaus, T. R. Degrado et al., "An evaluation of myocardial fatty acid and glucose uptake using PET with [18F]fluoro-6-thia-heptadecanoic acid and [18F]FDG in patients with congestive heart failure," Journal of Nuclear Medicine, vol. 42, no. 1, pp. 55-62, 2001.

[84] B. Renstrom, S. Rommelfanger, C. K. Stone et al., "Comparison of fatty acid tracers FTHA and BMIPP during myocardial ischemia and hypoxia," Journal of Nuclear Medicine, vol. 39, no. 10, pp. 1684-1689, 1998.

[85] T. R. DeGrado, M. T. Kitapci, S. Wang, J. Ying, and G. D. Lopaschuk, "Validation of 18F-fluoro-4-thia-palmitate as a PET probe for myocardial fatty acid oxidation: effects of hypoxia and composition of exogenous fatty acids," Journal of Nuclear Medicine, vol. 47, no. 1, pp. 173-181, 2006.

[86] T. R. DeGrado, F. Bhattacharyya, M. K. Pandey, A. P. Belanger, and S. Wang, "Synthesis and preliminary evaluation of $18-{ }^{18} \mathrm{~F}-$ fluoro-4-thia- oleate as a PET probe of fatty acid oxidation," The Journal of Nuclear Medicine, vol. 51, no. 8, pp. 1310-1317, 2010.

[87] L. H. Opie, "Effects of regional ischemia on metabolism of glucose and fatty acids. Relative rates of aerobic and anaerobic energy production during myocardial infarction and comparison with effects of anoxia," Circulation Research, vol. 38, no. 5, pp. 52-74, 1976.

[88] P. Camici, E. Ferrannini, and L. H. Opie, "Myocardial metabolism in ischemic heart disease: basic principles and application to imaging by positron emission tomography," Progress in Cardiovascular Diseases, vol. 32, no. 3, pp. 217-238, 1989.

[89] H. Iida, U. Ruotsalainen, M. Mäki et al., "F-18 fluorodeoxyglucose uptake and water-perfusable tissue fraction in assessment of myocardial viability," Annals of Nuclear Medicine, vol. 26, no. 8, pp. 644-655, 2012.

[90] M. Bousquenaud, F. Maskali, S. Poussier et al., "Acipimoxenhanced ${ }^{18} \mathrm{~F}$-fluorodeoxyglucose positron emission tomography for characterizing and predicting early remodeling in the rat infarct model," International Journal of Cardiovascular Imaging, vol. 28, no. 6, pp. 1407-1415, 2012.

[91] M. J. Knuuti, H. Yki-Jarvinen, L.-. Voipio-Pulkki et al., "Enhancement of myocardial [fluorine-18]fluorodeoxyglucose uptake by a nicotinic acid derivative," Journal of Nuclear Medicine, vol. 35, no. 6, pp. 989-998, 1994.

[92] M. J. Knuuti, P. Nuutila, U. Ruotsalainen et al., "The value of quantitative analysis of glucose utilization in detection of myocardial viability by PET," Journal of Nuclear Medicine, vol. 34, no. 12, pp. 2068-2075, 1993.

[93] A. Tawakol, R. Q. Migrino, G. G. Bashian et al., "In vivo ${ }^{18} \mathrm{~F}-$ fluorodeoxyglucose positron emission tomography imaging provides a noninvasive measure of carotid plaque inflammation in patients," Journal of the American College of Cardiology, vol. 48, no. 9, pp. 1818-1824, 2006.

[94] E. J. Battegay, "Angiogenesis: mechanistic insights, neovascular diseases, and therapeutic prospects," Journal of Molecular Medicine, vol. 73, no. 7, pp. 333-346, 1995.

[95] P. Carmeliet and R. K. Jain, "Molecular mechanisms and clinical applications of angiogenesis," Nature, vol. 473, no. 7347, pp. 298307, 2011.

[96] M. A. Schwartz, M. D. Schaller, and M. H. Ginsberg, "Integrins: emerging paradigms of signal transduction," Annual Review of Cell and Developmental Biology, vol. 11, pp. 549-599, 1995.
[97] P. C. Brooks, R. A. F. Clark, and D. A. Cheresh, "Requirement of vascular integrin $\alpha \mathrm{v} \beta 3$ for angiogenesis," Science, vol. 264, no. 5158, pp. 569-571, 1994.

[98] W. Cai and X. Chen, "Multimodality imaging of vascular endothelial growth factor and vascular endothelial growth factor receptor expression," Frontiers in Bioscience, vol. 12, no. 11, pp. 4267-4279, 2007.

[99] U. Tateishi, T. Oka, and T. Inoue, "Radiolabeled RGD peptides as integrin alpha(v)beta3-targeted PET tracers," Current Medicinal Chemistry, vol. 19, no. 20, pp. 3301-3309, 2012.

[100] M. R. Stacy, M. W. Maxfield, and A. J. Sinusas, "Targeted molecular imaging of angiogenesis in PET and SPECT: a review," Yale Journal of Biology and Medicine, vol. 85, no. 1, pp. 75-86, 2012.

[101] M. Rodriguez-Porcel, W. Cai, O. Gheysens et al., "Imaging of VEGF receptor in a rat myocardial infarction model using PET," Journal of Nuclear Medicine, vol. 49, no. 4, pp. 667-673, 2008.

[102] B. Wagner, M. Anton, S. G. Nekolla et al., "Noninvasive characterization of myocardial molecular interventions by integrated positron emission tomography and computed tomography," Journal of the American College of Cardiology, vol. 48, no. 10, pp. 2107-2115, 2006.

[103] H. Gao, L. Lang, N. Guo et al., "PET imaging of angiogenesis after myocardial infarction/reperfusion using a one-step labeled integrin-targeted tracer ${ }^{18}$ F-AlF-NOTA-PRGD2," European Journal of Nuclear Medicine and Molecular Imaging, vol. 39, no. 4, pp. 683-692, 2012.

[104] M. R. Makowski, U. Ebersberger, S. Nekolla, and M. Schwaiger, "In vivo molecular imaging of angiogenesis, targeting $\alpha \mathrm{v} \beta 3$ integrin expression, in a patient after acute myocardial infarction," European Heart Journal, vol. 29, no. 18, p. 2201, 2008.

[105] R. Haubner, W. A. Weber, A. J. Beer et al., "Noninvasive visualization of the activated $\alpha \mathrm{v} \beta 3$ integrin in cancer patients by positron emission tomography and $\left[{ }^{18} \mathrm{~F}\right]$ Galacto-RGD," PLoS Medicine, vol. 2, article e70, 2005.

[106] A. Almutairi, R. Rossin, M. Shokeen et al., "Biodegradable dendritic positron-emitting nanoprobes for the noninvasive imaging of angiogenesis," Proceedings of the National Academy of Sciences of the United States of America, vol. 106, no. 3, pp. 685-690, 2009.

[107] M. Hori, S. Sasayama, A. Kitabatake et al., "Low-dose carvedilol improves left ventricular function and reduces cardiovascular hospitalization in Japanese patients with chronic heart failure: the Multicenter Carvedilol Heart Failure Dose Assessment (MUCHA) trial," American Heart Journal, vol. 147, no. 2, pp. 324-330, 2004.

[108] R. M. de Jong, A. T. M. Willemsen, R. H. J. A. Slart et al., "Myocardial $\beta$-adrenoceptor downregulation in idiopathic dilated cardiomyopathy measured in vivo with PET using the new radioligand (S)-[ $\left[{ }^{11} \mathrm{C}\right] \mathrm{CGP} 12388$," European Journal of Nuclear Medicine and Molecular Imaging, vol. 32, no. 4, pp. 443447, 2005.

[109] M. Naya, T. Tsukamoto, K. Morita et al., "Myocardial $\beta$ adrenergic receptor density assessed by ${ }^{11} \mathrm{C}$-CGP12177 PET predicts improvement of cardiac function after carvedilol treatment in patients with idiopathic dilated cardiomyopathy," Journal of Nuclear Medicine, vol. 50, no. 2, pp. 220-225, 2009.

[110] D. S. Goldstein, J. E. Brush Jr., G. Eisenhofer, R. Stull, and M. Esler, "In vivo measurement of neuronal uptake of norepinephrine in the human heart," Circulation, vol. 78, no. 1, pp. 41-48, 1988. 
[111] G. J. Hasking, M. D. Esler, G. L. Jennings, D. Burton, J. A. Johns, and P. I. Korner, "Norepinephrine spillover to plasma in patients with congestive heart failure: evidence of increased overall and cardiorenal sympathetic nervous activity," Circulation, vol. 73, no. 4, pp. 615-621, 1986.

[112] S. Li, C. Holmes, I. J. Kopin, and D. S. Goldstein, "Aging-related changes in cardiac sympathetic function in humans, assessed by 6-18F-fluorodopamine PET scanning," The Journal of Nuclear Medicine, vol. 44, no. 10, pp. 1599-1603, 2003.

[113] D. S. Goldstein, C. Holmes, J. E. Stuhlmuller, J. W. M. Lenders, and I. J. Kopin, "6- $\left[{ }^{18} \mathrm{~F}\right]$ Fluorodopamine positron emission tomographic scanning in the assessment of cardiac sympathoneural function-studies in normal humans," Clinical Autonomic Research, vol. 7, no. 1, pp. 17-29, 1997.

[114] D. D. Gutterman, D. A. Morgan, and F. J. Miller, "Effect of brief myocardial ischemia on sympathetic coronary vasoconstriction," Circulation Research, vol. 71, no. 4, pp. 960-969, 1992.

[115] A. J. Luisi Jr., G. Suzuki, R. DeKemp et al., "Regional 11C-hydroxyephedrine retention in hibernating myocardium: chronic inhomogeneity of sympathetic innervation in the absence of infarction," Journal of Nuclear Medicine, vol. 46, no. 8, pp. 1368-1374, 2005.

[116] D. M. Raffel, R. A. Koeppe, Y. W. Jung et al., "Quantification of cardiac sympathetic nerve density with N-11C-guanyl-metaoctopamine and tracer kinetic analysis," Journal of Nuclear Medicine, vol. 54, pp. 1645-1652, 2013.

[117] H. R. Herschman, "Molecular Imaging: looking at Problems, Seeing Solutions," Science, vol. 302, no. 5645, pp. 605-608, 2003.

[118] F. Nensa, T. D. Poeppe, K. Beiderwellen et al., "Hybrid PET/MR imaging of the heart : feasibility and initial results," Radiology, vol. 268, no. 2, pp. 366-373, 2013.

[119] S. G. Nekolla, A. Martinez-Moeller, and A. Saraste, "PET and MRI in cardiac imaging: from validation studies to integrated applications," European Journal of Nuclear Medicine and Molecular Imaging, vol. 36, no. 1, pp. 121-130, 2009.

[120] B. R. Jarrett, B. Gustafsson, D. L. Kukis, and A. Y. Louie, "Synthesis of ${ }^{64} \mathrm{Cu}$-labeled magnetic nanoparticles for multimodal imaging," Bioconjugate Chemistry, vol. 19, no. 7, pp. 1496-1504, 2008.

[121] H. Lee, Z. Li, K. Chen et al., "PET/MRI dual-modality tumor imaging using arginine-glycine-aspartic (RGD)-conjugated radiolabeled iron oxide nanoparticles," The Journal of Nuclear Medicine, vol. 49, no. 8, pp. 1371-1379, 2008.

[122] T. Schindler and H. Schelbert, "Quantitation of myocardial perfusion: absolute blood flow versus relative uptake," in Atlas of Nuclear Cardiology, V. Dilsizian and J. Narula, Eds., pp. 145-194, Springer, New York, NY, USA, 2013. 


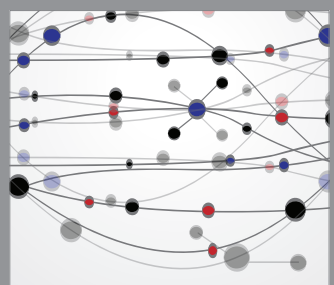

The Scientific World Journal
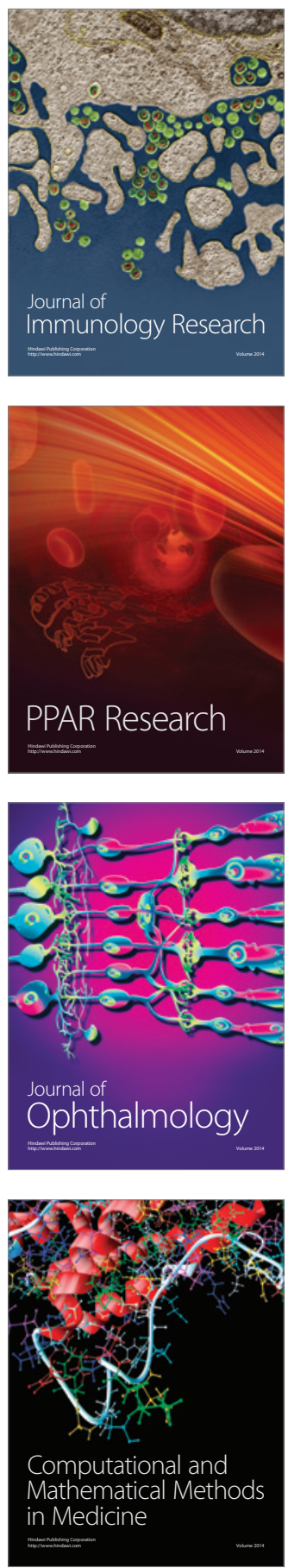

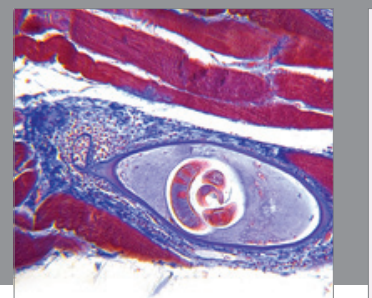

Gastroenterology

Research and Practice
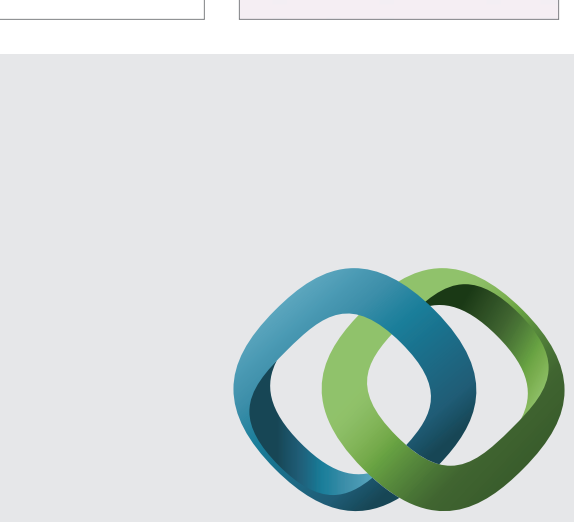

\section{Hindawi}

Submit your manuscripts at

http://www.hindawi.com
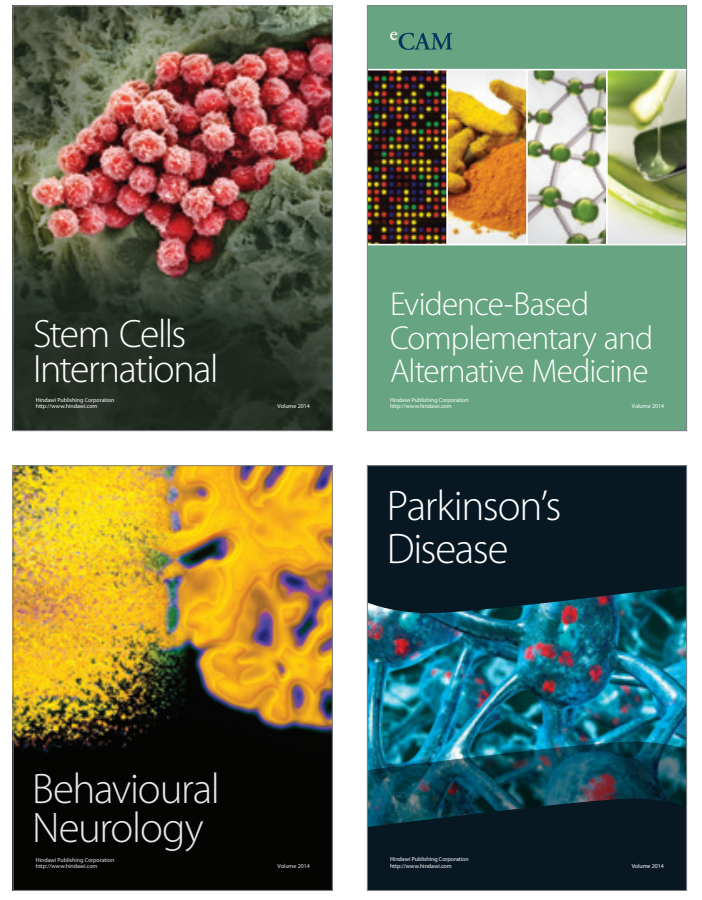
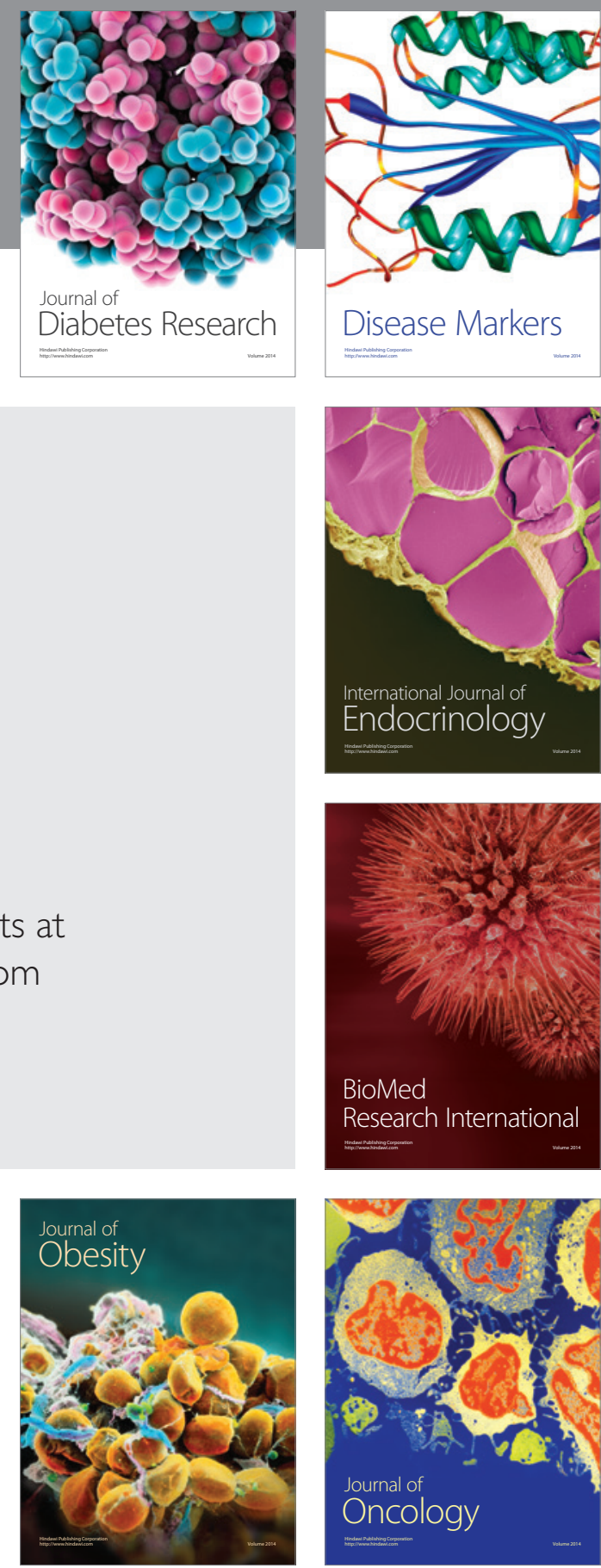

Disease Markers
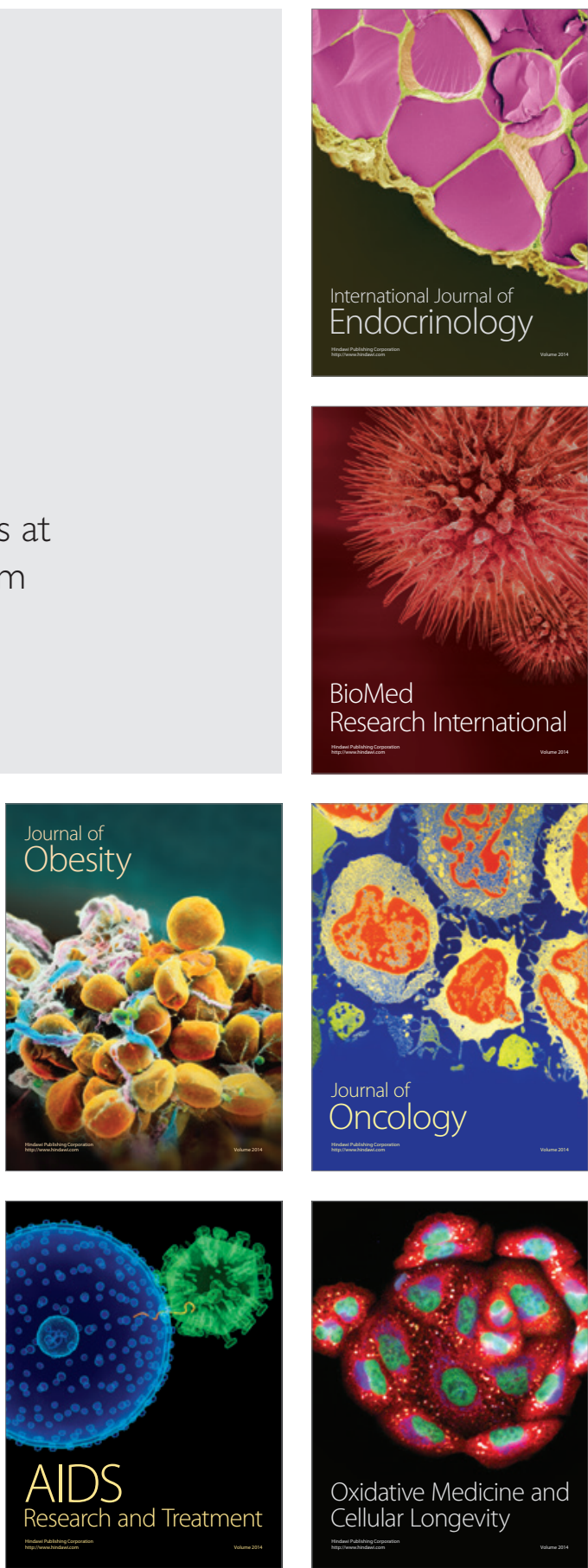